\title{
Low-Cost Flexible Packaging for High-Power Li-Ion HEV Batteries
}

\author{
by A.N. Jansen, K. Amine, and G.L. Henriksen
}

Argonne National Laboratory, Argonne, Illinois 60439

operated by The University of Chicago

for the United States Department of Energy under Contract W-31-109-Eng-38

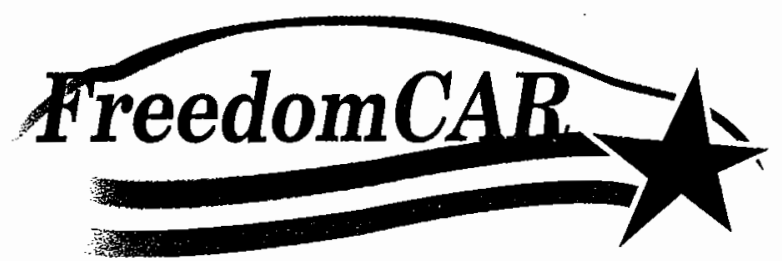

Freedom CAR \& Vehicle Technologies Office 
Argonne National Laboratory, a U.S. Department of Energy Office of Science laboratory, is operated by The University of Chicago under contract W-31-109-Eng-38.

\section{DISCLAIMER}

This report was prepared as an account of work sponsored by an agency of the United States Government. Neither the United States Government nor any agency thereof, nor The University of Chicago, nor any of their employees or officers, makes any warranty, express or implied, or assumes any legal liability or responsibility for the accuracy, completeness, or usefulness of any information, apparatus, product, or process disclosed, or represents that its use would not infringe privately owned rights. Reference herein to any specific commercial product, process, or service by trade name, trademark, manufacturer, or otherwise, does not necessarily constitute or imply its endorsement, recommendation, or favoring by the United States Government or. any agency thereof. The views and opinions of document authors expressed herein do not necessarily state or reflect those of the United States Government or any agency thereof.

Available electronically at http://www.osti.gov/bridge/

Available for a processing fee to U.S. Department of Energy and its contractors, in paper, from:

U.S. Department of Energy

Office of Scientific and Technical Information

P.O. Box 62

Oak Ridge, TN 37831-0062

phone: (865) 576-8401

fax: (865) 576-5728

email: reports@adonis.osti.gov 


\begin{abstract}
ANL-04/09
ARGONNE NATIONAL LABORATORY

9700 S. Cass Ave.

Argonne, IL 60439

\section{Low-Cost Flexible Packaging for High-Power Li-Ion HEV Batteries}

by

A.N. Jansen, K. Amine, and G.L. Henriksen

Electrochemical Technology Program

Chemical Engineering Division

June 2004 


\section{ACKNOWLEDGEMENTS}

This work was supported by the U.S. Department of Energy's FreedomCAR \& Vehicle Technologies Office under contract No. W-31-109-ENG-38. Special thanks are owed to Takehiro Hosokawa, Keiichi Tanaka, and Haruo Saen of Sumitomo Electric Flat Components, Inc. (a subsidiary of Sumitomo Electric Industries, Ltd.) for their generous contribution of packaging materials and assembled pouches, and to Stephen W. Cornell of Plastic Technology Partners for his valuable consultations. Major contributors are listed below and key industrial contacts are listed in Appendix E.

\begin{tabular}{|l|l|}
\hline Argonne National Laboratory & Sumitomo Electric Flat Components, Inc.(SEI) \\
Don Vissers & Takehiro Hosokawa \\
Aron Newman & Keiichi Tanaka \\
David Chaiko & Haruo Saen \\
Emo Redey & Koji Hanafusa (Judd Wire Inc.) \\
Paul Nelson & Kim Tran (Judd Wire Inc.) \\
Dennis Dees & \\
Stan Johnson & \\
\hline Department of Energy & Rollprint Packaging Products, Inc. \\
Tien Duong & Dhuanne Dodrill \\
David Howell & Karen Berger \\
\hline Plastic Technology Partners & \\
Steve Cornell & FreedomCAR Energy Storage Tech Team \\
& Ted Miller \\
& Bill Schank \\
\hline
\end{tabular}




\section{GLOSSARY OF TERMS}

ANL

ASI

DEC

DMC

EC

EMC

$\mathrm{EVOH}$

Gen $1(+)$

Gen $1(-)$

Gen 1 Electrolyte

Gen $2(+)$

Gen $2(-)$

Gen 2 Electrolyte

HDPE

$\mathrm{HEV}$

$\mathrm{HF}$

HPPC test

LDPE

LiBOB

LLDPE

LP40 electrolyte

MCMB

MDPE

PBT

PC

PE

PET

PP

ppm

PVDF binder

$\mathrm{RH}$

SEI
Argonne National Laboratory

Area specific impedance (ohm- $\mathrm{cm}^{2}$ )

Diethyl carbonate

Dimethyl carbonate

Ethylene carbonate

Ethyl methyl carbonate

Ethyl vinyl alcohol

$\mathrm{LiNi}_{0.8} \mathrm{Co}_{0.2} \mathrm{O}_{2}$ cathode

MCMB:SFG-6 (82:18)

LP40

$\mathrm{LiNi}_{0.8} \mathrm{Co}_{0.15} \mathrm{Al}_{0.05} \mathrm{O}_{2}$ cathode

MAG-10 synthetic graphite anode

1.2 $\mathrm{M} \mathrm{LiPF}_{6}$ EC:EMC (3:7)

High density polyethylene

Hybrid electric vehicle

Hydrogen fluoride (hydrofluoric acid)

Hybrid pulse power characterization test

Low density polyethylene

Lithium bis (oxalato) borate

Linear low-density polyethylene

1.0 M LiPF 6 EC:DEC (50:50)

Mesocarbon microbeads

Medium density polyethylene

Polybutylene terephthalate

Propylene carbonate

Polyethylene

Polyethylene terephthalate (polyester)

Polypropylene

Parts per million (by weight)

Polyvinylidene fluoride

Relative humidity

Sumitomo Electric Flat Components, Inc. (a subsidiary of Sumitomo Electric Industries, LTD.) 


\section{CONTENTS}

Page

ACKNOWLEDGEMENTS ........................................................................................ ii

GLOSSARY OF TERMS ........................................................................................... iii

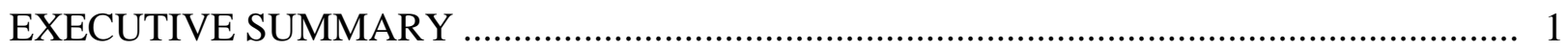

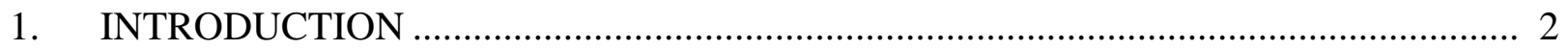

1.1 Laminate Description................................................................................... 2

1.2 Pouch Description............................................................................... 4

2. PACKAGING TEST PROTOCOLS ..................................................................... 7

2.1 Storage at $55^{\circ} \mathrm{C}$ and Dry Conditions............................................................... 7

2.2 Storage at $55^{\circ} \mathrm{C}$ and $83 \%$ Relative Humidity ................................................. 8

2.3 Thermal Cycling between $-40^{\circ} \mathrm{C}$ and $60^{\circ} \mathrm{C}$ at Ambient Humidity ......................... 8

2.4 Moisture and Acid Titration of Electrolyte Samples .......................................... 9

2.5 Controlled Pressure Release ............................................................................ 10

2.6 Temperature Rise of Feed-throughs (Cross-sectional Area) .................................. 10

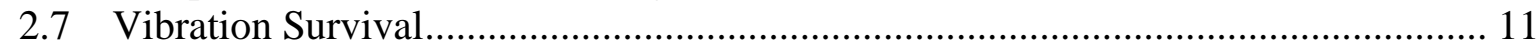

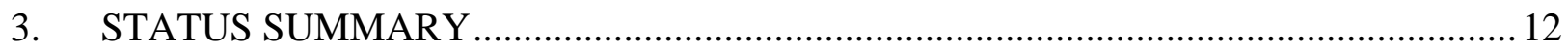

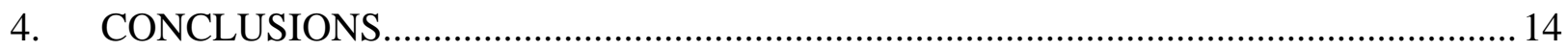

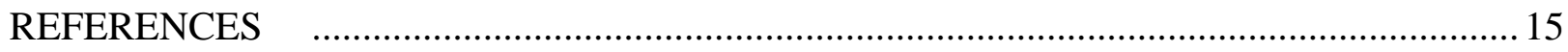

APPENDIX A. POUCH SCREENING DEVELOPMENT .................................................. 16

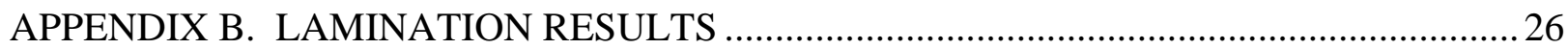

APPENDIX C. FEED-THROUGH DESIGN CRITERIA .............................................. 31

APPENDIX D. TESTING OF SUMITOMO ELECTRIC INDUSTRY'S POUCHES .............33

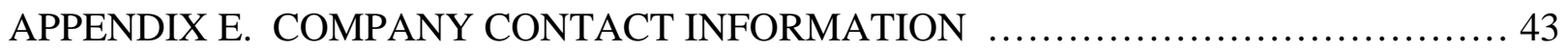




\section{TABLES}

Page

1. Flexible packaging survival goals...................................................................... 1

2. Comparison of the strength and cost of commercial substrates......................................... 17

3. Milligrams of cation exchanged by lithium per gram of molecular sieve ........................2 25

4. Solvent-cast and two-part adhesives cast on Al foil and soaked in electrolyte

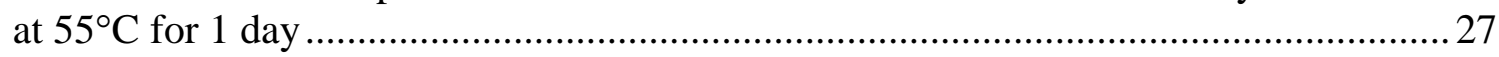

5. Hot-melt adhesives (and PP \& PE) cast on Al foil and soaked in electrolyte at $55^{\circ} \mathrm{C}$ for 1 day 28

6. Tie-layer adhesives cast on $\mathrm{Al}$ foil and soaked in electrolyte at $55^{\circ} \mathrm{C}$ for 1 day ..............28

7. Candidate adhesives cast on $\mathrm{Al}$ foil and soaked in electrolyte at $55^{\circ} \mathrm{C}$ in inert gas glove box

8. Polypropylene adhesion to pretreatments applied to $\mathrm{Al}$ foil and soaked in electrolyte at $55^{\circ} \mathrm{C}$

9. Analysis of electrolyte from SEI's HEV-sized pouches that underwent rapid thermal cycling between $-40^{\circ} \mathrm{C}$ and $60^{\circ} \mathrm{C}$ in ambient humidity.....

10. Analysis of electrolyte from SEI's HEV-sized pouches that underwent storage at $55^{\circ} \mathrm{C}$ and $83 \% \mathrm{RH}$

\section{FIGURES}

1. Cross-section of a simple multi-layered laminate

2. Cross-section of an elaborate multi-layered laminate ................................................... 4

3. Schematic of a typical laminate pouch cell with four heat zones and stamped pocket for the cell assembly

4. Schematic of a typical laminate pouch cell with three heat zones that form an

elliptical tube.

5. Electrolyte vapor-permeation data from Mocon for selected single films and one first generation laminate.

6. Schematic of test method used to evaluate small laminates in controlled environments and photo of typical laminate and film pouches used in this study .........20

7. Solvent weight loss in $15-\mu \mathrm{m}$ nylon/ $25-\mu \mathrm{m} \mathrm{Al} / 50-\mu \mathrm{m}$ PP pouches over time as a function of temperature...

8. Summarized loss rates for first generation laminates obtained from pouch weight loss tests for water inside and EC/PC/EMC inside.....

9. Water and HF concentration levels inside pouches filled with electrolyte after two weeks in a $100 \%$ humidity environment for first generation laminates

10. Moisture levels and acid levels resulting from intentional doping of electrolyte with 1,000 and 10,000 ppm of water

11. Weight gain of various molecular sieves exposed to DEC solvent .................................25

12. Feed-through design that minimizes circumference of electrodes and minimizes distortion of laminate face

13. HEV-sized pouch from SEI with feed-throughs and electrolyte 
14. Humidity control using saturated aqueous solution of potassium nitrate .......................34

15. $\quad$ Programmed temperature profile used for rapid thermal cycling ................................34

16. Programmed temperature profiles for summer/winter thermal cycling .........................35

17. Temperature measurements inside pouch electrolyte and in Tenney Jr. temperature chamber for summer thermal cycling in a sealed plastic container at $~ 90 \% \mathrm{RH}$...........36

18. Temperature measurements inside pouch electrolyte and in Tenney Jr. temperature chamber for rapid thermal cycling in ambient humidity

19. Weight of SEI's HEV-sized pouches undergoing rapid thermal cycling between $-40^{\circ} \mathrm{C}$ and $60^{\circ} \mathrm{C}$ in ambient humidity

20. Weight of SEI's HEV-sized pouches undergoing storage at $55^{\circ} \mathrm{C}$ and $83 \% \mathrm{RH}$............38

21. Weight of SEI's HEV-sized pouches undergoing summer/winter thermal cycling profile.

22. Electrolyte-filled small pouches made from SEI laminate stock: weight vs. time at three temperatures and loss rate vs. temperature 


\section{EXECUTIVE SUMMARY}

The U.S. Department of Energy sponsors the Advanced Technology Development (ATD) Program to assist industrial developers of high-power lithium-ion batteries to overcome the barriers of cost, calendar life, and abuse tolerance so that this technology may be rendered practical for use in hybrid electric vehicles (HEVs) and fuel cell electric vehicles (FCEVs) under the FreedomCAR Partnership. Considerable cost savings can be realized if the metal container used in lithium-based batteries is replaced with a flexible multi-laminate containment commonly used in the food packaging industry. This laminate structure must have air, moisture, and electrolyte barrier capabilities, be resistant to HF attack, and be heat-sealable. Table 1 lists the criteria that must be met by the complete packaging system if it is to be acceptable for a HEV battery. This battery is required to have a calendar life of 15 years and operate between $-30^{\circ} \mathrm{C}$ and $52^{\circ} \mathrm{C}$. More information on the battery criteria can be found in the "FreedomCAR Battery Test Manual for Power Assist Hybrid Electric Vehicles,” DOE/ID-11069, October, 2003.

Table 1. Flexible packaging survival goals

\begin{tabular}{|l|c|c|c|c|}
\hline \multicolumn{1}{|c|}{ Criteria $^{*}$} & Units & Minimum & Desired & Protocol \\
\hline Electrolyte Loss Rate at $55^{\circ} \mathrm{C}$ and Dry & g/cm/year & 0.007 & 0.003 & 2.1 \\
\hline Survival at $55^{\circ} \mathrm{C}$ and $83 \% \mathrm{RH}$ & days & 300 & 600 & 2.2 \\
\hline $\begin{array}{c}\text { Survival of Thermal Cycling between } 60^{\circ} \mathrm{C} \\
\text { and -40 }{ }^{\circ} \mathrm{C} \text { at Ambient Humidity }\end{array}$ & cycles & $\begin{array}{c}2500 \\
(1 \text { year })^{\dagger}\end{array}$ & $\begin{array}{c}5000 \\
(2 \text { years })^{\dagger}\end{array}$ & 2.3 \\
\hline $\begin{array}{l}\text { Electrolyte Property after Testing } \\
\text { Acisture }\end{array}$ & $\begin{array}{c}<100 \\
\text { ppm (HF) }\end{array}$ & $\begin{array}{c}<400 \\
<200\end{array}$ & 2.4 \\
\hline Controlled Pressure Release & atm & 1 & 2 & 2.5 \\
\hline $\begin{array}{l}\text { Cross-Sectional Area of Feed-Throughs: } \\
\text { (for 25- kW battery) }\end{array}$ & Aluminum & $\begin{array}{c}0.15 \\
0.24\end{array}$ & TBD & 2.6 \\
\hline Vibration Survival & cycles & TBD & TBD & 2.7 \\
\hline
\end{tabular}

*Package must be complete, i.e., fully formed to shape (if used) with electrode feed-throughs, with pressure relief mechanism, and $\sim 50 \mathrm{~g}$ of electrolyte inside (for a $25-\mathrm{kW}$ battery). Cell components (negative and positive electrodes and separator) are optional for evaluation of packaging material, but must be included for final validation testing of complete cell/battery assembly. Approximate dimensions of a cell in a 25-kW battery are 100 x 110 x $20 \mathrm{~mm}$.

${ }^{\dagger}$ Estimated duration of test to achieve targeted number of thermal cycles. 


\section{INTRODUCTION}

Batteries with various types of chemistries are typically sold in rigid hermetically sealed containers that, at the simplest level, must contain the electrolyte while keeping out the exterior atmosphere. However, such rigid containers can have limitations in packaging situations where the form of the battery is important, such as in hand-held electronics like personal digital assistants (PDAs), laptops, and cell phones. Other limitations exist as well. At least one of the electrode leads must be insulated from the metal can, which necessitates the inclusion of an insulated metal feed-through in the containment hardware. Another limitation may be in hardware and assembly cost, such as exists for the lithium-ion batteries that are being developed for use in electric vehicles (EVs) and hybrid electric vehicles (HEVs). The large size (typically 10-100 Ah) of these batteries usually results in electric beam or laser welding of the metal cap to the metal can. The non-aqueous electrolyte used in these batteries are usually based on flammable solvents and therefore require the incorporation of a safety rupture vent to relieve pressure in the event of overcharging or overheating. Both of these features add cost to the battery.

Flexible packaging provides an alternative to the rigid container. A common example of this is the multi-layered laminates used in the food packaging industry, such as for vacuumsealed coffee bags. However, flexible packaging for batteries does not come without concerns. One of the main concerns is the slow egress of the electrolyte solvent through the face of the inner laminate layer and at the sealant edge. Also, moisture and air could enter from the outside via the same method. These exchanges may be acceptable for brief periods of time, but for the long lifetimes required for batteries in electric/hybrid electric vehicles, batteries in remote locations, and those in satellites, these exchanges are unacceptable.

Argonne National Laboratory (ANL), in collaboration with several industrial partners, is working on low-cost flexible packaging as an alternative to the packaging currently being used for lithium-ion batteries [1,2]. This program is funded by the FreedomCAR \& Vehicle Technologies Office of the U.S. Department of Energy. (It was originally funded under the Partnership for a New Generation of Vehicles, or PNGV, Program, which had as one of its mandates to develop a power-assist hybrid electric vehicle with triple the fuel economy of a typical sedan.) The goal in this packaging effort is to reduce the cost associated with the packaging of each cell several-fold to less than $\$ 1$ per cell ( $\sim 50$ cells are required per battery, 1 battery per vehicle), while maintaining the integrity of the cell contents for a 15-year lifetime. Even though the battery chemistry of main interest is the lithium-ion system, the methodology used to develop the most appropriate laminate structure will be very similar for other battery chemistries.

\subsection{LAMINATE DESCRIPTION}

Flexible packaging containers are assembled from rolls or sheets of multi-layered laminates, which are usually manufactured by converting companies. At its simplest, multilayered laminates consist of a thin metal film that has a protective polymer film on one side for exterior scratch resistance and a heat-sealable polymer film on the other side, which becomes the interior side after the packaging container (pouch) is made. A cross-section of this laminate is 
shown in Figure 1. The outer protective layer is usually a nylon or polyester material that is on the order of 10 to 40 microns thick. The inner sealant layer is usually a polyolefin (polyethylene, polypropylene, etc.) that is 20 to 40 microns thick. The metal layer is usually aluminum foil on the order of 5 to 30 microns thick.

Most laminate designs will not be as simple as that in Figure 1. Often the layers are laminated together with an adhesive material. There may also be two layers of metal foil to minimize the effect of pinholes and an additional polymer barrier layer (such as polyester) to protect the metal foil from the electrolyte. Adhesives may be present between these layers as well (as shown in Figure 2). The adhesive layer may be a polymer that is either a thermoset or thermoplastic material, in which case it is often referred to as a tie layer. It could also be a solvent-cast adhesive or glue. Often, a pretreatment is done to the metal surface to create an oxide layer that has better adhesion to the polymer layer. The laminate developer may also rely solely on corona discharge treatment of the polymer sealant layer, in which case the adhesive layer will not be present, only an interface. The adhesive layer is generally on the order of a few microns thick when used. The integrity of the layer interfaces is of paramount importance; delamination will result in rapid pouch failure. Appendix B presents a summary of lamination results.

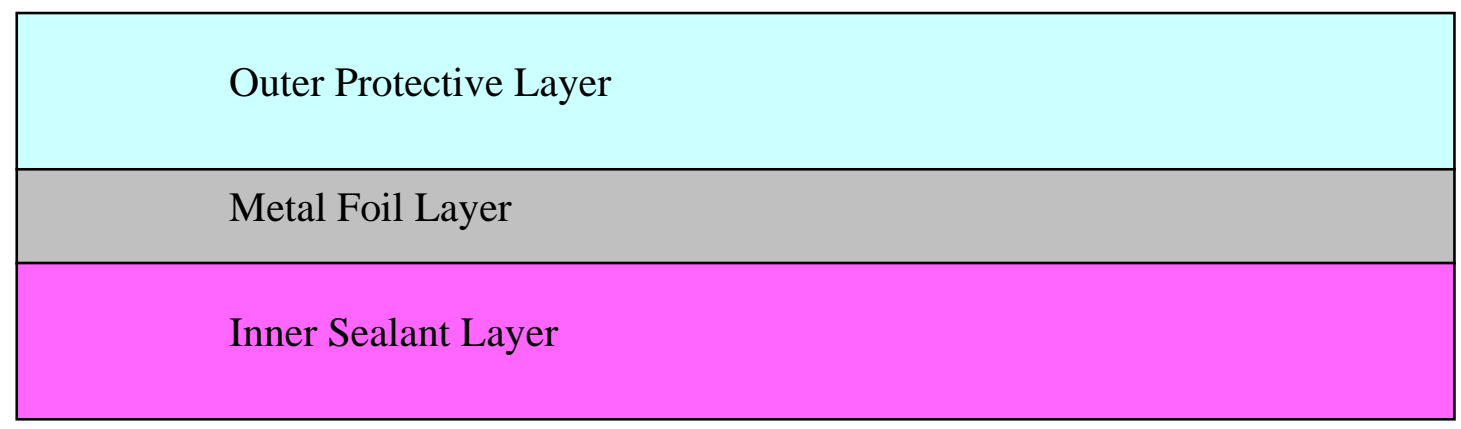

Figure 1. Cross-section of a simple multi-layered laminate.

Moisture adsorbents and acid getters may be incorporated into the laminate (and pouch) design. They are usually homogeneously dispersed in the sealant layer. Care must be taken in their application and the confidence one places in them. They may create defects in the sealant layer if they are not distributed uniformly or become solvent highways once they are saturated. Experiments must be conducted to guarantee that the adsorbent does not getter solvents from the electrolyte, as this would lead to a cell starved of electrolyte. Evidence also suggests that the moisture adsorbents are effective at removing the water molecules from the liquid electrolyte but are not completely effective at neutralizing their damaging effects. Electrolyte may still permeate to the adsorbent particle, react with the trapped water molecule, and form hydrofluoric acid. This is not meant to imply that adsorbents are ineffective, but that one should not rely too heavily on their use. They most likely will extend the life of the packaging material, but tests should be conducted on pouches made from laminates with and without adsorbents to confirm this. The most effective method to prevent moisture attack of the electrolyte is to stop the moisture ingress 
at the pack or module level. Appendix A provides more insight on the moisture-acid relationship and information on moisture adsorbents.

\begin{tabular}{|l|}
\hline Outer Protective Layer \\
\hline Adhesive Layer, Metal Pretreatment, or Interface \\
\hline Metal Foil Layer \\
\hline Adhesive Layer \\
\hline Metal Foil Layer \\
\hline Adhesive Layer, Metal Pretreatment, or Interface \\
\hline Electrolyte Barrier Layer \\
\hline Adhesive Layer or Interface \\
\hline Inner Sealant Layer with Adsorbents \\
\hline
\end{tabular}

Figure 2. Cross-section of an elaborate multi-layered laminate.

\subsection{POUCH DESCRIPTION}

The laminate stock mentioned above is cut into sheets that will be used to form the pouch. Two packaging designs are available to the battery developer. The first is made from two separate sheets (or one sheet folded in half). The positive electrode, separator/electrolyte, and negative electrode are stacked or wound into a cell assembly. Electrode leads, with a sealant material encircling their midsection, are attached to the positive and negative electrodes of the cell assembly. The cell assembly is placed between the laminate sheets with the sealant sides facing the cell assembly, and the electrode leads extending out such that their sealant material lies within the heat-seal zone. Due to the relatively large thickness of the HEV-sized cell, a pocket may be stamped into at least one of the faces of the pouch to make room for the cell assembly. Electrolyte is then added if the electrolyte is a liquid. All four edges of the pouch can then be heat-sealed at the same time. A vacuum is typically applied to the pouch immediately before the heat is applied to reduce void space and impregnate the electrode and separator pores with electrolyte. The final pouch cell will be similar to that shown in Figure 3. 


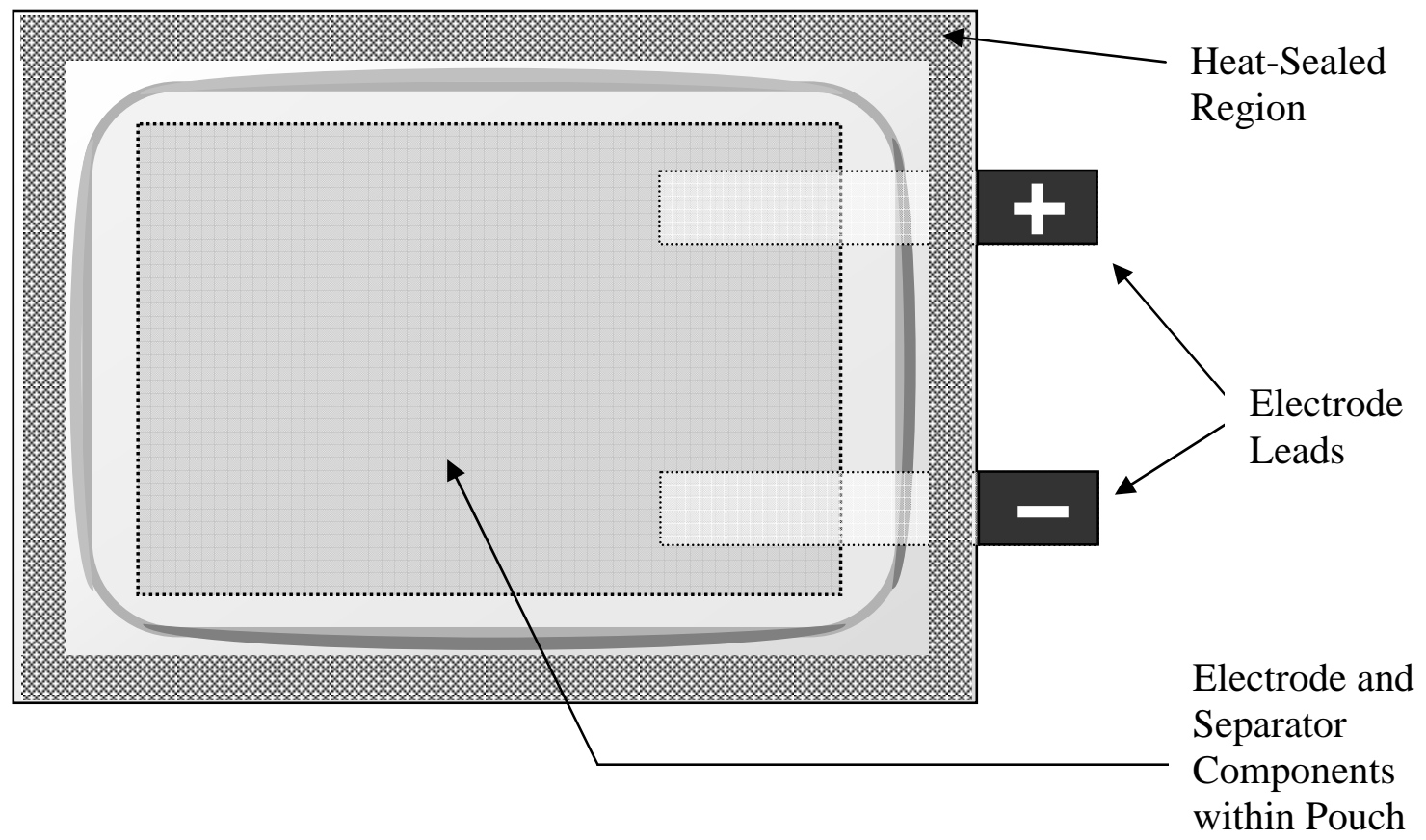

Figure 3. Schematic of a typical laminate pouch cell with four heat zones and stamped pocket for the cell assembly.

The second pouch design involves only three heat-seal regions and can be made without a stamped pocket for the cell assembly. One laminate sheet is folded lengthwise (with the sealant layer facing in) and heat-sealed along the long edge to form an elliptical tube. The cell assembly is placed inside the tube with the electrode leads extending out such that their sealant material lies within the heat-seal zone. Because of the elliptical shape of the tube, a stamped pocket is not needed for this design. Electrolyte is then added (if needed) and the top and bottom edges are heat-sealed simultaneously or sequentially. A vacuum is typically applied to the pouch immediately before the last edge is sealed to reduce void space and impregnate the electrode and separator pores with electrolyte. The final pouch cell will be similar to that shown in Figure 4. Variations are available in this design with regard to the position of the lengthwise seam. This seam can be located in the center of the cell assembly face or positioned to one side. Each method has its own drawbacks. More module space is used if the seam is allowed to jut out to the side, which can be minimized if the seam is gently folded over and secured. The seam down the middle creates a "fin" that makes it more difficult to heat-seal the top and bottom edges, and leakage at the junction point is more likely. Note that the elliptical tube design may result in excess material at both the top and bottom if a pocket is not stamped into the laminate sheet. 

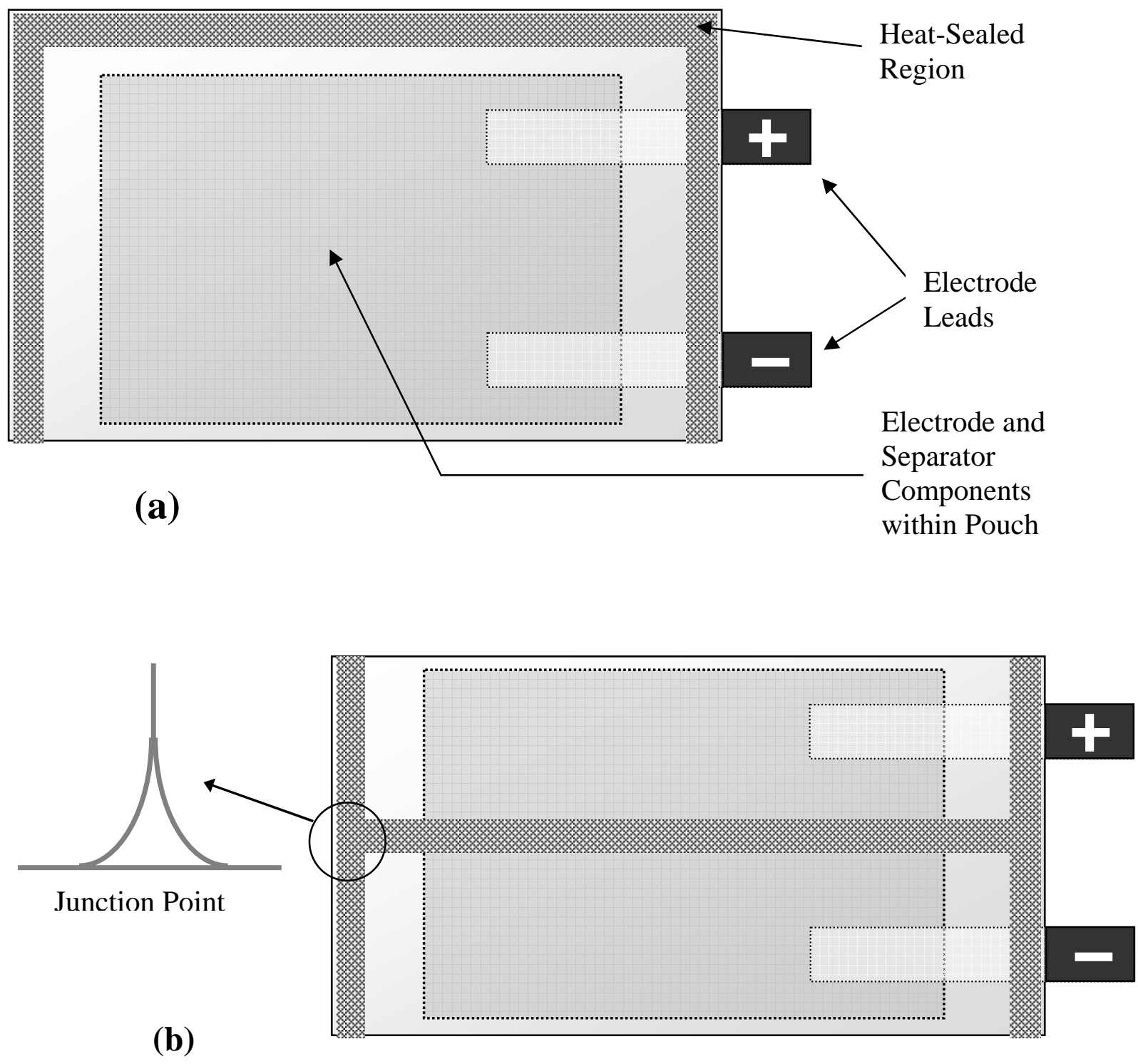

Figure 4. Schematic of a typical laminate pouch cell with three heat zones that form an elliptical tube around the cell assembly: (a) lengthwise seam located at the side; (b) lengthwise seam located at the middle ("fin" seal). 


\section{PACKAGING TEST PROTOCOLS}

Flexible packaging has been used widely in the food and beverage industry for the last several decades. As a result, the permeation rates of most polymer materials have been evaluated for moisture, oxygen, and carbon dioxide - the permeants of interest with regard to food and beverage spoilage. Test methods were developed to quantify these permeation rates and many reference books are available that tabulate these data (e.g., see References 3 and 4). However, little information is available in the literature that tabulates the permeation rates of the electrolytes used in advanced lithium-based systems. Application of the standard testing methods used by the food industry was found to be inappropriate, as discussed in Appendix A. As a result, new packaging test protocols were needed to accurately reflect the conditions of interest to battery developers.

The test protocols below are intended to be performed on packages (cell pouches) that are complete, i.e., fully formed to shape with electrode feed-throughs, with pressure relief mechanism, and $\sim 50 \mathrm{~g}$ of electrolyte inside (for a $25-\mathrm{kW}$ battery). Cell components (negative and positive electrodes and separator) are optional for evaluation of packaging material, but must be included for final validation testing of the complete cell/battery assembly. The electrolyte used in the pouches must be of the same composition that the battery developer intends to use in the final battery. Many of the studies discussed in the appendixes used a blend of five major carbonates to incorporate the effects of each, since the final electrolyte composition is not specified. It is assumed that the approximate dimensions of a HEV-sized cell in a 25-kW battery are $100 \mathrm{x}$ $110 \times 20 \mathrm{~mm}$. These dimensions (and the quantity of electrolyte) are meant only for guidance; the battery developer is free to vary them but must prove that the overall battery design meets the FreedomCAR \& Vehicle Technologies Office power and energy targets.

\subsection{STORAGE AT $55^{\circ} \mathrm{C}$ AND DRY CONDITIONS}

At least ten pouches will be stored horizontally at $55^{\circ} \mathrm{C}$ in a sealable container that contains Type $13 \mathrm{X}$ molecular sieve beads. A storage temperature of $55^{\circ} \mathrm{C}$ was selected because of evidence that the electrolyte salt $\left(\mathrm{LiPF}_{6}\right)$ begins to decompose above this temperature. It is recommended that the molecular sieve be placed under a perforated false bottom such that it does not come into contact with the pouches. The pouches should be stacked horizontally on wire racks, spacers, or grates to maximize the exposed surface area of each pouch. Type 13X molecular sieve adsorbs moisture and carbonate solvents almost equally. This guarantees a constant driving force for permeation of the electrolyte solvent out of the package without the interfering effect of moisture permeating into it. The molecular sieve should be replaced or regenerated monthly or more frequently if it is believed to be saturated. This type of sieve will hold approximately $25 \%$ of its dry weight in moisture or DEC solvent.

The pouches will be weighed every two weeks and inspected for signs of rupture or delamination over the duration of one year. Each pouch should be allowed to cool to room temperature in the closed container before weighing to prevent ambient moisture uptake. The pouches must be weighed to at least a $1-\mathrm{mg}$ resolution, preferably a $0.1-\mathrm{mg}$ resolution, in a relatively dry or air-conditioned room. It is recommended that a 100 -g standard weight be weighed at each biweekly weighing to test the balance for drift over time. Electrolyte loss rate 
will be determined from the slope of the pouch weight vs. storage time and reported in units of grams of electrolyte loss per centimeter of pouch perimeter. The developer should also consider performing this protocol at two additional temperatures (e.g., $30^{\circ} \mathrm{C}$ and $40^{\circ} \mathrm{C}$ ) so that extrapolations to room temperature (or operating temperature) can be made.

\subsection{STORAGE AT $55^{\circ} \mathrm{C}$ AND 83\% RELATIVE HUMIDITY}

At least eighteen pouches will be stored horizontally at $55^{\circ} \mathrm{C}$ in a sealable container that contains saturated aqueous solutions of potassium nitrate. A storage temperature of $55^{\circ} \mathrm{C}$ was selected because of evidence that the electrolyte salt $\left(\mathrm{LiPF}_{6}\right)$ begins to decompose above this temperature. It is recommended that the $\mathrm{KNO}_{3}$ solution be kept in an open pan and placed under a perforated false bottom such that it does not come into contact with the pouches. Enough solution should be used to guarantee that the container would be at $83 \%$ relative humidity (the solution will dry out if it is undersized). Water should be added to the $\mathrm{KNO}_{3}$ solution if it becomes dry. More information about this solution is provided in Appendix D. The pouches should be stacked horizontally on wire racks, spacers, or grates to maximize the exposed surface area of each pouch. The $\mathrm{KNO}_{3}$ solution guarantees a constant driving force for permeation of the moisture into the pouch. This is the most aggressive test that the battery packaging must survive. Electrolyte permeates out while moisture permeates in; where they meet will result in acid formation due to electrolyte-moisture reactions (for most salts used in lithium-ion batteries).

The pouches will be weighed every two weeks and inspected for signs of rupture or delamination over duration of one year. Each pouch should be allowed to cool to room temperature on an open grate to allow the surface-absorbed moisture to evaporate before weighing. The pouches must be weighed to at least a 1-mg resolution, preferably a 0.1-mg resolution, in a relatively dry or air-conditioned room. It is recommended that a 100 -g standard weight be weighed at each biweekly weighing to test the balance for drift over time. Rate of weight change will be determined from the slope of the pouch weight vs. storage time and reported in units of milligrams of weight change per centimeter of pouch perimeter per year. There will be a net balance due to weight loss from electrolyte evaporation and weight gain from water uptake. Each month one pouch should be selected randomly to undergo destructive testing. The electrolyte should be extracted with a dry plastic (not glass) syringe or by cutting the bottom corner. It should be stored in a Nalgene bottle (not glass) placed in a desiccator or dry glove box while it awaits analysis for moisture, acid level, and discoloration (described in Section 2.4). The empty pouch should be rinsed out, dried, and saved for pressure testing (described in Section 2.5). At least six pouches should remain on test indefinitely to establish the physical survival time of the pouch.

\subsection{THERMAL CYCLING BETWEEN $-40^{\circ} \mathrm{C}$ AND $60^{\circ} \mathrm{C}$ AT AMBIENT HUMIDITY}

At least eighteen pouches will be thermally cycled between $-40^{\circ} \mathrm{C}$ and $60^{\circ} \mathrm{C}$ in a temperature chamber under ambient humidity conditions. This test protocol evaluates the effect of the thermal coefficient mismatch that exists between the polymer materials and metal foil and feed-throughs. It also tests the effects of absorbed moisture and electrolyte crystallizing in the

sealant/adhesive layer. An upper temperature of $60^{\circ} \mathrm{C}$ was selected in this protocol (instead of 
$55^{\circ} \mathrm{C}$ ) because the electrolyte salt $\left(\mathrm{LiPF}_{6}\right)$ is at this higher limit for less than half the test time and the resulting amount of salt decomposition is considered acceptable. The pouches should be stacked horizontally on wire racks, spacers, or grates to maximize the exposed surface area of each pouch. A container to control the humidity is not used in this test because of the large thermal lag it would impose. It is critical that the battery developer demonstrates that the electrolyte inside the pouch truly reaches the temperature limits of the thermal cycle. More about this topic can be found in Appendix D. As guidance, the pouch should rest at $-40^{\circ} \mathrm{C}$ for an additional 60 to 90 minutes after the temperature chamber reaches $-40^{\circ} \mathrm{C}$ and the same for the $60^{\circ} \mathrm{C}$ limit.

The pouches will be weighed every 200 thermal cycles and inspected for signs of rupture or delamination over duration of one year. Each pouch should be allowed to cool to room temperature before weighing. The pouches must be weighed to at least a 1-mg resolution, preferably a 0.1-mg resolution, in a relatively dry or air-conditioned room. It is recommended that a 100-g standard weight be weighed at each weighing to test the balance for drift over time. Rate of weight change will be determined from the slope of the pouch weight vs. number of thermal cycles and reported in units of micrograms of weight change per centimeter of pouch perimeter per thermal cycle. There will be a net balance due to weight loss from electrolyte evaporation and weight gain from water uptake. Each month one pouch should be selected randomly to undergo destructive testing. The electrolyte should be extracted with a dry plastic (not glass) syringe or by cutting the bottom corner. It should be stored in a Nalgene bottle (not glass) placed in a desiccator or dry glove box while it awaits analysis for moisture, acid level, and discoloration (described in Section 2.4). The empty pouch should be rinsed, dried, and saved for pressure testing (described in Section 2.5). At least six pouches should remain on test indefinitely to establish the physical survival time of the pouch.

\subsection{MOISTURE AND ACID TITRATION OF ELECTROLYTE SAMPLES}

Moisture titration is best performed with a routine Karl Fischer titrator, preferably using methanol-based anolytes and catholytes. This may vary depending on the model available and the vendor recommendations. It will be necessary to store the electrolyte samples in a dry glove box or desiccator and handle them in a dry room or, preferably, a dry glove box (or bag). Lithium-ion electrolytes are very hygroscopic. Each sample should be titrated at least twice. The value reported is in parts per million by weight of $\mathrm{H}_{2} \mathrm{O}$ in electrolyte.

Acid titration is performed with a traditional burette using a $0.02 \mathrm{~N}$ sodium hydroxide $(\mathrm{NaOH})$ aqueous solution. A 5-mL burette with graduations of $0.01 \mathrm{~mL}$ is recommended. An appropriate indicator is bromothymol blue (0.04 wt.\% in water), which is yellow at $\mathrm{pH}<6$ and turns blue at $\mathrm{pH}>7$. A dry plastic syringe ( $1 \mathrm{~mL}$ size) and plastic Erlenmeyer flask (50 mL) is used when handling electrolyte samples to prevent the reaction of glass with possible hydrofluoric (HF) acid. Polypropylene is preferred. This titration technique is best done by first placing approximately $3 \mathrm{~mL}$ of crushed ice ( $\mathrm{pH}$ neutral) in the plastic Erlenmeyer with approximately $1 \mathrm{~mL}$ of pH-neutral water and a couple drops of indicator. Approximately $0.2 \mathrm{~mL}$ of electrolyte are drawn into the plastic syringe, weighed to $0.1 \mathrm{mg}$ accuracy, and expelled onto the ice slurry. The flask is swirled while the $\mathrm{NaOH}$ solution is carefully metered out through the burette. Addition of the $\mathrm{NaOH}$ drops should stop immediately when the slurry color turns to a 
slight blue tint (from yellow). If after 30 seconds the color returns to yellow, more $\mathrm{NaOH}$ should be added (usually one or two additional drops is enough). Note that the color will eventually turn yellow again if time is allowed to pass or if the slurry warms up. It is best to do this titration as quickly as possible and make sure that ice remains present in the slurry. The empty syringe is then weighed to obtain the electrolyte sample weight. The acid level is easily calculated with the assumption that it is pure HF. Each sample should be titrated at least twice. The value reported is in parts per million by weight of HF in electrolyte.

Discoloration of each electrolyte sample should be recorded by photographing it against a white reference background (under similar lighting conditions). It is important to maintain a constant background as reference so that at the end of the year a direct comparison can be made among samples. A tan-colored paint strip (available at a hardware store) should be photographed next to each sample. The photographs can then be digitally adjusted later to account for changes in lighting.

\subsection{CONTROLLED PRESSURE RELEASE}

The pressure that the pouch will vent through its relief mechanism, or rupture, must be determined. This pressure is best determined by attaching a tube in some manner to the bottom corner or edge of the pouch. The method used to attach the tube depends on the design of the pouch and the discretion of the battery developer. Gas is applied to the tube through a regulator and the pressure is increased at a slow pace until the pouch vents or ruptures. Key observations to report are the pressure reached in units of atm (above ambient) and the location of the pressure release (vent device, seam rupture, face rupture, or leakage at feed-through seam). This test should be performed on new empty pouches as a control, as well as on abused pouches from test protocols in Sections 2.2 and 2.3.

\subsection{TEMPERATURE RISE OF FEED-THROUGHS (CROSS-SECTIONAL AREA)}

The temperature of the electrode feed-throughs must be kept below the softening point of the polymer sealant material. This situation could be violated during charge and discharge pulses through the cell if the feed-throughs are undersized. A simple model was developed that assumes the heat generated is adiabatic during a 149-amp pulse for 18 seconds (25-kW battery discharge pulse). This implies that the $\mathrm{I}^{2} \mathrm{R}$ heat generated cannot dissipate fast enough during the brief duration of the pulse. The model's parameters were electrical conductivity, heat capacity, and volume for copper and aluminum metal. For this heat generation, a minimum cross-sectional area was established that maintains the temperature rise at less than $10^{\circ} \mathrm{C}$. Keep in mind that the cell chemistry inside the pouch will also generate heat that may be dissipated through the feedthroughs as well. The area values listed in the Executive Summary are meant as guidance; it remains the battery developer's responsibility to demonstrate that its cell feed-throughs remain below a safe temperature throughout testing. As a side note, the IR voltage drop across the feedthroughs is relatively insignificant, if the temperature rise is adequately addressed. Feed-through design criteria are discussed in Appendix C. 


\subsection{VIBRATION SURVIVAL}

The pouch cell must survive vibrations that are normally experienced by transportation vehicles. At this point in time it is believed that testing an individual pouch cell would not be a realistic test. The cell would be restrained in a module and the module restrained in a battery pack. It would be best to use the same vibration test protocols that the auto industry routinely uses on its power trains, but at the battery module or pack testing level. 


\section{STATUS SUMMARY}

This report on low-cost packaging is the first widely distributed version and is intended to give the battery industry a synopsis of the concerns that exist in flexible battery packaging and methods to evaluate proposed packaging designs. It is hoped that battery developers will try these test protocols and provide comments for improvements. Feedback and additional observations will be incorporated into a future revision. Comments for its improvement are encouraged and greatly appreciated.

Efforts to develop low-cost flexible packaging are ongoing at ANL. There are several areas of concern or interest that have not yet been adequately addressed. To date, only carbonate solvents (DMC, DEC, EMC, EC, PC) have been investigated. The effects of non-carbonate solvent and additives that are present in lithium-ion, lithium polymer, gel (plasticized), and siloxane electrolytes need to be studied. Other lithium salts also need to be considered, particularly those that do not form HF. The method used to cool the battery will influence the packaging integrity, e.g., will the cooling fluid be ambient air that may contain moisture, pollutants, and occasional salt spray, or will the package be in direct contact with dielectric oil?

Alternative test protocols may need to be developed. For instance, helium leak-testing, which is often used to test metal battery containers, has been considered, but has not yet been explored in this project. Unlike metals, polymers do allow molecules to slowly permeate through them, and these rates vary depending on the molecule, polymer, humidity, and temperature. Is the rate of helium permeation an accurate reflection of electrolyte permeation?

It is generally assumed that flexible packaging will lower the cost of the container hardware and cell assembly process. This is certainly true if pouches used in the food and beverage industry are adequate. However, if elaborate designs, materials, and processes must be implemented to make flexible packaging feasible for batteries, will the cost savings still be worthwhile? A full cost analysis must be done for an acceptable pouch technology at production levels of 5,000,000 pouches ( 100,000 battery packs).

Collaboration continues with Sumitomo Electric Industries (SEI). Their battery pouches were of great usefulness in developing and field-testing the protocols outlined in this report. Detailed results of these tests are summarized in Appendix D. Their battery pouches were found to be well developed and suited for long-term battery use. A few concerns were identified in the course of testing their pouches and were brought to their attention. The most notable concern is the cracking that developed at the pocket corners that were stamped into the laminate sheets. SEI is in the process of changing the thickness of some of the layers in the laminate and retooling the die used to form the pouch pockets to ameliorate pocket corner cracking. When these improvements have been completed, ANL will test this new generation of pouches under the test protocols described in this report. Several pouches will also be made that contain the relatively new salt lithium bis (oxalato) borate, commonly referred to as LiBOB. This salt is not capable of forming $\mathrm{HF}$, and thus should provide an interesting comparison with pouches that contain $\mathrm{LiPF}_{6}$ based electrolytes. SEI will also be in an ideal position to provide a true cost analysis of flexible packaging in HEV batteries. 
Organoclay nanocomposites are being investigated in this packaging project for their use as a sealant layer with improved barrier properties. An organoclay is simply a blend of an organic compound with natural clay. The main emphasis in this development area is to design a surfactant that will lead to complete exfoliation of the clay into the polymer matrix. Surfactants were tailor-made in this program for use in LDPE, HDPE, and EVOH nanocomposites. From this work, the oxygen and carbon dioxide barrier properties of these organoclay nanocomposite films show improvements $(>30 \%)$ at very low loading levels compared with control films. The addition of homogeneously dispersed organoclays in LDPE and HDPE resulted in a significant increase $(\sim 50 \%)$ in crystallinity at loading levels less than 2 vol.\% clay. However, no barrier improvement to date has been observed for moisture or electrolyte. More information can be found about the organoclay project in Reference 5. 


\section{CONCLUSIONS}

The FreedomCAR calendar life goal of 15 years for the HEV battery under various abuse conditions poses a significant challenge to the conventional flexible packaging approach. Nonetheless, the potential for considerable cost savings offered by flexible packaging cannot be overlooked. New test protocols were developed to aid battery and packaging developers in meeting this challenge. Flexible laminates do show good potential to be a replacement for the traditional rigid container that is used in present long-term organic-solvent batteries. However, it is very important that the complete flexible package system be subjected to accelerated abuse testing, in particular thermal abuse testing. Key areas to monitor are signs of excessive electrolyte permeation, delamination of the sealant layer from the metal foil, seam splitting, electrolyte creep at the feed-throughs, and reactions between the laminate and the cell components (electrolyte, active materials, and current collectors). The best indicator of the packaging performance is the quality of the electrolyte upon completion of the test protocols outlined in Section 2 of this report. 


\section{REFERENCES}

1. A. N. Jansen, K. Amine, A. E. Newman, D. R. Vissers, and G. L. Henriksen, Journal of Materials, 54 (3), 29-32 (2002).

2. A. N. Jansen, K. Amine, D. J. Chaiko, G. L. Henriksen, T. Hosokawa, K. Tanaka, and H. Saen, Proceedings of the 204th Meeting of the Electrochemical Society, Orlando, FL, Oct. 12-17, 2003 (in press).

3. $\quad$ Plastics Design Library (PDL), Permeability and Other Film Properties, PDL Handbook Series, Norwich, NY, 1995.

4. J. Brandrup, E. H. Immergut, and E. A. Grulke (Eds.), Polymer Handbook, $4^{\text {th }}$ ed., John Wiley \& Sons, Inc., New York, 1999.

5. D. J. Chaiko, Proceedings of the 204th Meeting of the Electrochemical Society, Orlando, FL, Oct. 12-17, 2003 (in press).

6. J. N. Epel, J. M. Margolis, S. Newman, R. B. Seymour (Editorial Steering Committee), Engineered Materials Handbook, Vol. 2, "Engineering Plastics," in ASM International, $4^{\text {th }}$ printing (1997).

7. H. F. Brinson (Technical Chairman), Engineered Materials Handbook, Vol. 3, “Adhesives and Sealants,” in ASM International, $2^{\text {nd }}$ printing (1999).

8. T. G. Sherwood, R. L. Pigford, and C. R. Wilke, Mass Transfer, McGraw-Hill, p.70 (1975).

9. L. Reich and S. S. Stivala, Elements of Polymer Degradation, McGraw-Hill, New York (1971).

10. L. Greenspan, Journal of Research of the National Bureau of Standards-A, 81A(1), pp. 89-96 (1977). 


\section{APPENDIX A: POUCH SCREENING DEVELOPMENT}

The packaging concept used at ANL is based on plastic laminate technology that consists of using an aluminum metal foil to form the support base for applying polymeric coatings. The layers of the laminate work synergistically to create a cell packaging material that has chemical resistance, heat sealability, and high rupture strength. The required properties of this laminate are as follows:

- A moisture barrier, which prevents ambient moisture from penetrating into the cell and reacting with electrolyte.

- An electrolyte barrier layer, which prevents electrolyte solvents from leaking out of the cell. Typical solvents used in the lithium-ion system are ethylene carbonate (EC), dimethyl carbonate (DMC), diethyl carbonate (DEC), ethyl methyl carbonate (EMC), and propylene carbonate (PC).

- A hydrogen fluoride (HF) barrier layer, which prevents any HF present in the electrolyte from attacking the pouch support materials. (HF is formed if moisture comes in contact with many of the electrolytes used in lithium ion batteries.)

- A sealant layer, which provides the seal between the laminates and also seals the laminates to the electrode leads (tabs), via a simple and inexpensive hot press process.

Ideally, all of the desired barrier and sealant characteristics listed above would be incorporated into one film layer. In terms of importance, the loss of electrolyte solvent from the flexible cell package is one of the primary concerns for the cycle life and calendar life of the cell (battery), if not the primary concern. This phenomenon could lead to cell starvation and performance degradation. The solvent could potentially exit the pouch by three means: (1) across the laminate, (2) through the edges where the two laminates are sealed together, and (3) at the electrode leads where they seal to the pouch. In addition, the permeation of the solvent across the laminate could lead to the degradation of the adhesive layers that bond the barrier films together, resulting in film delamination and mechanical failure.

Another primary concern is the permeation of moisture into the packaging. Potential pathways for moisture entry are the same as those mentioned above for solvents exiting the pouch. Moisture permeation could cause degradation of the polymer sealant layer, the formation of $\mathrm{HF}$ due to the decomposition of the lithium hexafluorophosphate $\left(\mathrm{LiPF}_{6}\right)$ salt used in most electrolytes, and the reaction with lithium species from the negative electrode to form hydrogen. The overall result is a degradation of cell life and performance.

\section{$\underline{\text { Pressure Relief }}$}

Gases are often generated during the initial charge or discharge of many battery chemistries and during abuse conditions such as overcharging or overheating. The cell container must be able to retain an expected amount of gas pressure under normal operating conditions but must safely vent pressure above a specified limit to prevent a physical explosive condition. This limit can be as high as 2 to 3 atmospheres. The goal here is to develop seals (or an area of the seal) that will yield at a safe pressure, similar to rupture disks in present-day metal containers, which are a critical pressure relief safety component of the cells. Therefore, the pouch containment could eliminate the need for this expensive safety vent. Not only must the seal 
strength be tailored to the system demands, but the laminate strength must also be considered. Simple force calculations on a pressurized sphere tell us that the force at any plane through the sphere is proportional to the radius squared. Hence, as the size of the cell increases, the wall thickness rapidly increases to a point where the laminated pouch can no longer be considered flexible. This may be fine for many cases so long as the pouch is still low in cost.

However, it is desirable to strengthen the wall as much as possible while maintaining some level of flexibility and low cost. A look at several common materials used in the laminating industry illustrates this point (Table 2). Oriented polyethylene terephthalate, also referred to as polyester or PET, meets most of these criteria. It is nearly four times stronger than aluminum foil, at half the density and at a fraction of the volumetric cost.

Table 2. Comparison of the strength and cost of commercial substrates.

\begin{tabular}{|lllll|}
\hline Polymer & $\begin{array}{l}\text { Yield } \\
\text { Strength } \\
\text { (psi) }\end{array}$ & $\begin{array}{l}\text { density } \\
\left(\mathbf{g} / \mathbf{c m}^{\mathbf{3}}\right)\end{array}$ & $\mathbf{\$ / l b}$ & $\mathbf{\$ / \mathbf { m } ^ { \mathbf { 3 } }}$ \\
PET & $\mathbf{2 7 0 0 0}$ & $\mathbf{1 . 3 9}$ & $\mathbf{0 . 6 5}$ & \\
Al foil & 7000 & 2.7 & 1.92 & 1990 \\
Nylon6 & 7000 & 1.15 & 0.67 & 1700 \\
PP & 6100 & 1.07 & 0.38 & 1900 \\
HDPE & 4000 & 0.95 & 0.5 & 1050 \\
LDPE & 2400 & 0.92 & 0.49 & 1000 \\
\hline
\end{tabular}

\section{$\underline{\text { Screening Methodology }}$}

A simple approach was taken to identify the most appropriate sealant film to use as the interior layer or, in other words, find the polymer film that provides the best barrier to transmission of the battery solvent and is still heat-sealable. Extensive data are available in the literature $[3,4]$ for water, oxygen, and carbon dioxide transmission rates through polymers, as these are the species of primary interest to the food and beverage industry. Unfortunately, such data are not available for many of the solvents used in the relatively new non-aqueous batteries. Thus, a practical method of screening numerous commercial polymer films was needed. Measuring the weight loss of solvent filled pouches over time proved to be quite effective.

The films to be investigated were made into pouches by heat-sealing two $7.6 \mathrm{~cm} \mathrm{x} 7.6 \mathrm{~cm}$ sheets together on three sides, filling with the solvent of interest, and sealing the final side. For these initial screens, only pure DEC was used. The pouches were stored at room temperature and their weights were measured as a function of time. Based on these screenings, several candidate polymers were identified (see Reference 6 for polymer definitions): polyethylene (high density, HDPE; medium density, MDPE; low density, LDPE; and linear low density, LLDPE), polypropylene (PP), polyethylene terephthalate (PET), ethyl vinyl alcohol (EVOH), Surlyn (Zn ionomer by Dupont), polyacrylonitrile (PAN), polyvinyldene fluoride (PVDF), and Nylon6 (a 
polyamide). Several of these candidate films were later dismissed as sealant layers for various reasons. The best sealant polymers were found to be polyolefin-based (PE, PP, and their acidmodified copolymers).

Mocon, Inc., an industrial vendor that specializes in barrier analysis of polymers, was enlisted to confirm these initial screening results. They modified their film diffusion cell apparatus in accordance with ASTM standards to test the permeation of electrolyte vapors through the polymer film samples identified above. The tests were performed at elevated temperature and extrapolated to room temperature (Figure 5), assuming an Arrhenius relationship. (The assumption of an Arrhenius relationship does not hold if the polymer approaches its glass transition temperature.) In general, these electrolyte vapor results agreed with the initial pouch screening with DEC only.

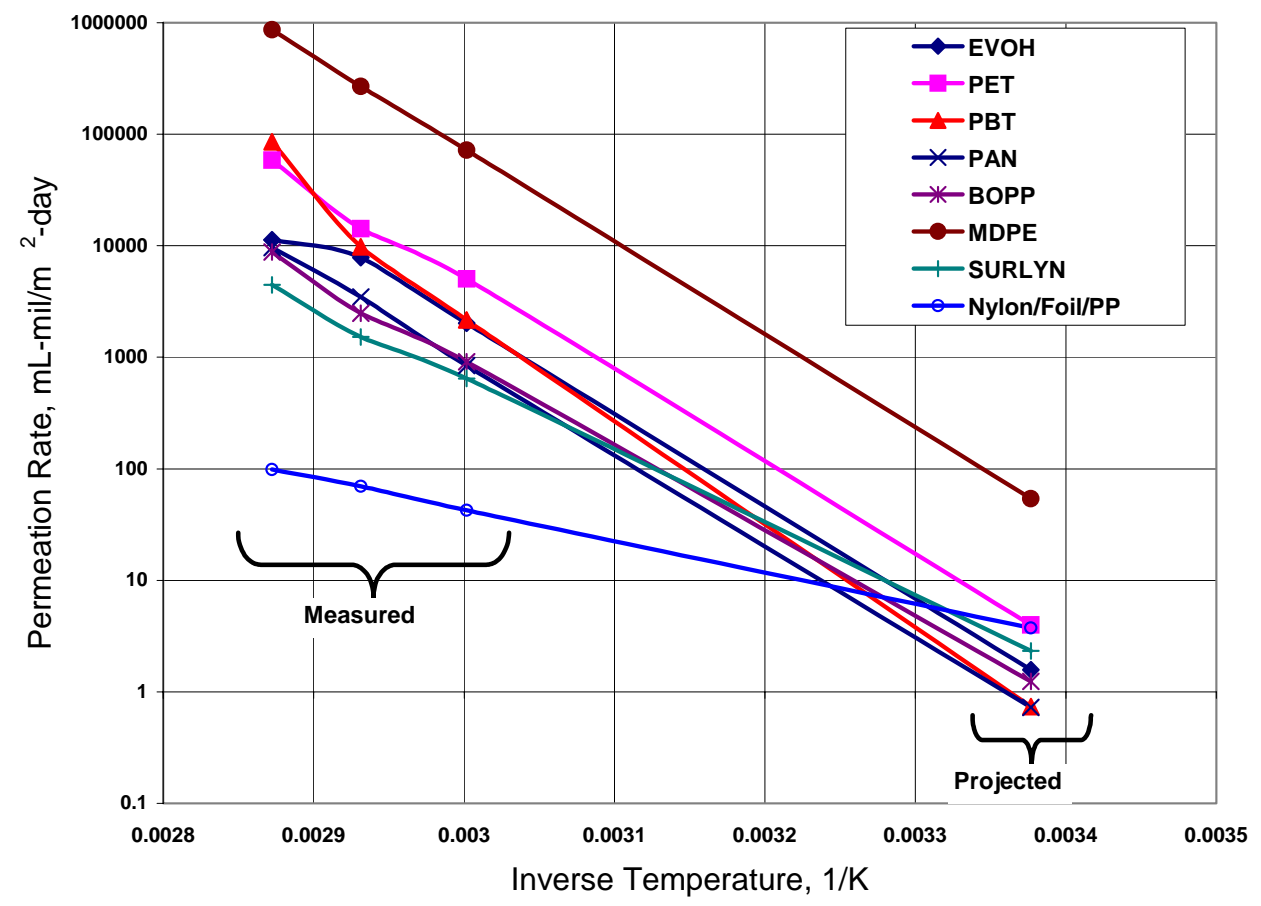

Figure 5. $1 \mathrm{M} \mathrm{LiPF}_{6}$ in EC/DEC/PC/EMC electrolyte vapor permeation data from Mocon, Inc., for selected single films and one first-generation laminate extrapolated to room temperature. Volume is vapor-corrected to STP.

A key observation was made at this early point in the project: the method in which this test is orientated is very important, i.e., is the film in contact with liquid phase or vapor phase? A prime example is the results for the PAN film shown in Figure 5, which were obtained with vapor phase contact only. At first, this film appeared to have ideal barrier properties, but it dissolved when it came in contact with liquids that contained EC. Mocon did not observe this fact in the ASTM vapor phase test because EC has a very low vapor pressure. Unfortunately, EC is a critical component of nearly all lithium-ion cell electrolytes. This one observation set the framework for the majority of the testing protocols in this report; a true abuse test must include contact of the liquid phase. 


\section{$\underline{\text { Initial Laminate Development }}$}

The initial approach to laminate construction used in this project consisted of using an aluminum foil as the substrate onto which a sealant film is laminated on one side and a tough polymer film is applied on the other side. The tough film, typically oriented polyester, serves as an exterior scratch-resistant protective film and provides extra rupture strength to the package. Nylon is sometimes used in the packaging industry as the protective exterior layer; however, its high water absorption rate could adversely affect the calendar life of lithium-based cells. So although it was used in some pouch prototypes, no reason was found to continue using nylon in subsequent designs. Several designs included the addition of a second foil layer. The general scheme thus consisted of four layers: an exterior polyester, two aluminum foils ( typically 9-25 $\mu \mathrm{m}$ thick), and an interior polymer sealant film. An adhesive was used to bond them together.

Using two thin layers of aluminum instead of one thicker foil provides an extra layer of protection by minimizing the effect of pinholes. The likelihood of pinholes in each foil aligning is remote. As proof, the water transmission rate through a single $9-\mu m$-thick aluminum foil was measured in a controlled humid environment to be $0.07 \mathrm{mg} \cdot \mathrm{mil} / \mathrm{m}^{2} \cdot \mathrm{d}$, but through a laminate of foil/adhesive/foil it was reduced by more than 3 times to $0.02 \mathrm{mg} \cdot \mathrm{mil} / \mathrm{m}^{2} \cdot \mathrm{d}$. Using a thicker foil could reduce the effects of pinholes because the density of pinholes decreases with foil thickness; however, if the foil is too thick, the packaging suffers from lack of flexibility, cost, and poor heat sealing due to the high thermal conductivity of aluminum. Nevertheless, the calculated quantity of water entering a double-foil (9- $\mu \mathrm{m} \mathrm{Al}$ ) laminate pouch measuring $10 \mathrm{~cm}$ by $20 \mathrm{~cm}$ (the general dimensions of a 10-Ah high-power cell) is 2 grams over a 15-year period. Therefore, there is a need for further enhancement of the barrier property.

A decision was made to have several multi-layer laminates manufactured by an industrial converter company, Rollprint Packaging Products Inc. (Addison, IL). Screening results indicated that PET was an excellent solvent barrier, but due to its high crystallinity it has poor sealant characteristics. Thus, an additional layer of sealant film was necessary for the two rolls that

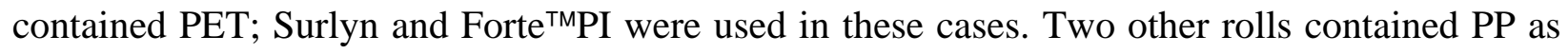
the sealant/barrier layer. On one roll, PP was laminated onto a double Al foil (9 $\mu \mathrm{m}$ each) substrate and on the other it was laminated onto a single, thicker $(25 \mu \mathrm{m})$ foil substrate. In this manner, a direct comparison of double and single foils could be made. Only one of the five laminate rolls contained a double layer of $9-\mu \mathrm{m} \mathrm{Al}$ foil; the rest used single layers of $25 \mu \mathrm{m} \mathrm{Al}$ foil. Oriented PET was used as the outer protective film on the Al foil for one of the rolls; for the the rest, nylon was used. These layers were joined together using a solvent-based adhesive in which the solvents were driven off and the films joined together under pressure and temperature in standard laminate roll converting equipment.

\section{Laminate Pouch Test Method}

A test matrix was established to evaluate the performance of each of the Rollprint prototype laminates. It consisted of filling 7.6- $\mathrm{cm} \times 7.6-\mathrm{cm}$ pouches with $2 \mathrm{~mL}$ of one of three liquids: water, EC/PC/EMC solvent, or $1 \mathrm{M} \mathrm{LiPF}_{6}$ in EC/PC/DEC/EMC electrolyte. (Subsequent experiments used blends of all five carbonate solvents, i.e., DEC/DMC/EMC/EC/PC.) The heatsealing of each pouch was performed at Rollprint with its equipment and personnel. Pouches that 
contained water were placed in a sealed jar with drierite under a false bottom to create a constant driving force for moisture permeation out of the pouches. Likewise, pouches that contained solvent were each placed in a sealed jar with Type $13 \mathrm{X}$ molecular sieve under a false bottom to create a constant driving force for solvent permeation out of the pouches. Type 13X molecular sieve was selected based on earlier work that demonstrated its affinity for adsorption of DEC. Pouches from each laminate were stacked in jars as shown in Figure 6, with pipe cleaners between each pouch to maximize exposed area. Paper or tape labels on the pouches were not used because of their tendency to absorb moisture and solvents, which would interfere with the accuracy of weight measurement. Markers were used instead to label each pouch.

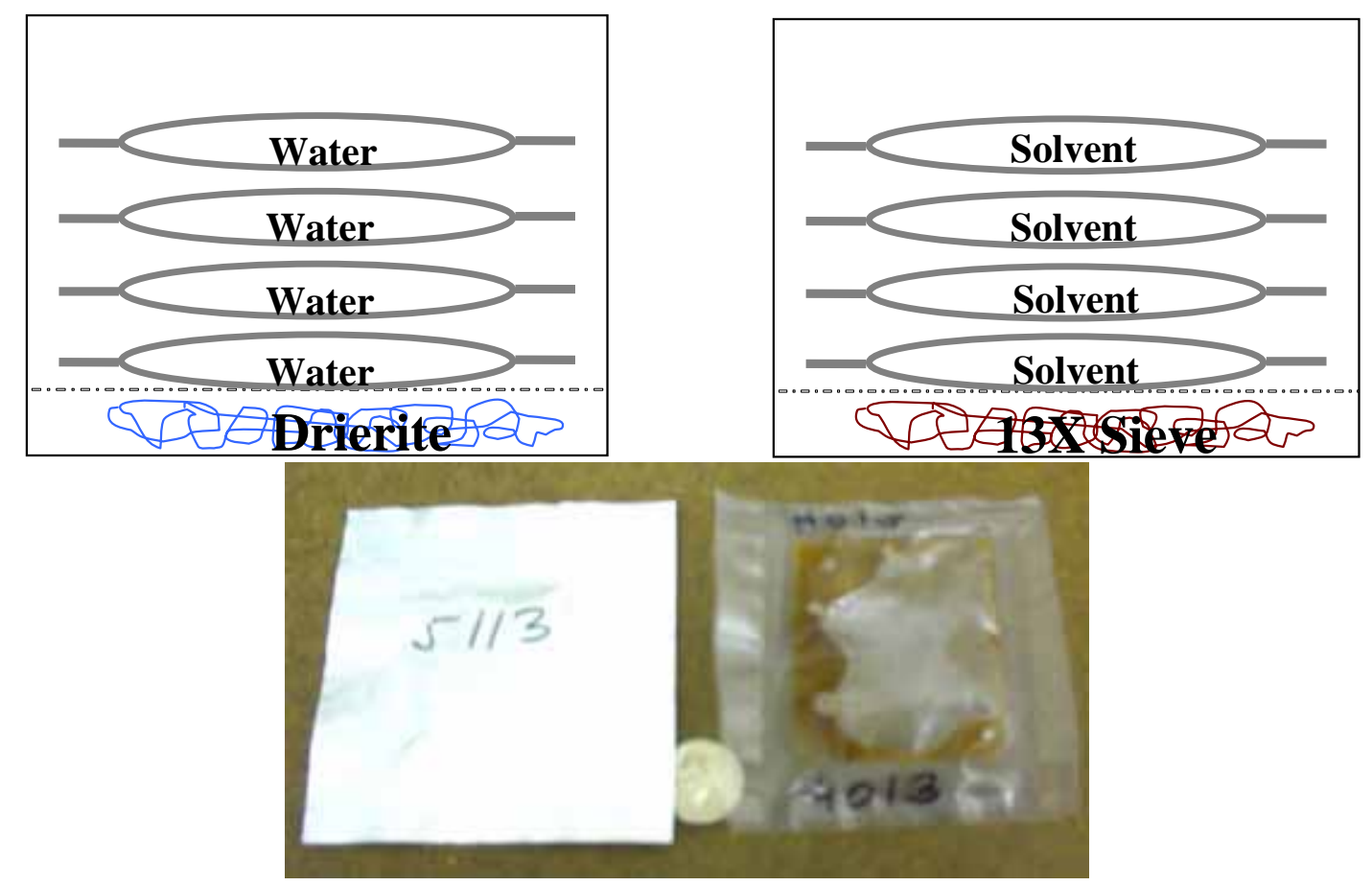

Figure 6. Schematic of test method used to evaluate small laminates in controlled environments. Photo of typical laminate and film pouches used in this study.

Weight loss analysis was performed for the water- and solvent-filled pouches at three temperatures: $37^{\circ} \mathrm{C}, 50^{\circ} \mathrm{C}$, and $72^{\circ} \mathrm{C}$. (Subsequent experiments used temperatures of ambient, $37^{\circ} \mathrm{C}$, and $55^{\circ} \mathrm{C}$.) The weight decreased with time in a very linear manner for each of the pouches (see Figure 7, solvent-filled pouch). A permeation rate was obtained from the slope of each line. The results of this simple test matrix are best summarized graphically as in Figures 8a and $8 \mathrm{~b}$. In these graphs, the permeation rates are based on the total length of the pouch perimeter. The pouch area was not used because it was assumed that all of the transmission loss is through the seal edge and not through the two faces of the pouch due to the aluminum layer. 


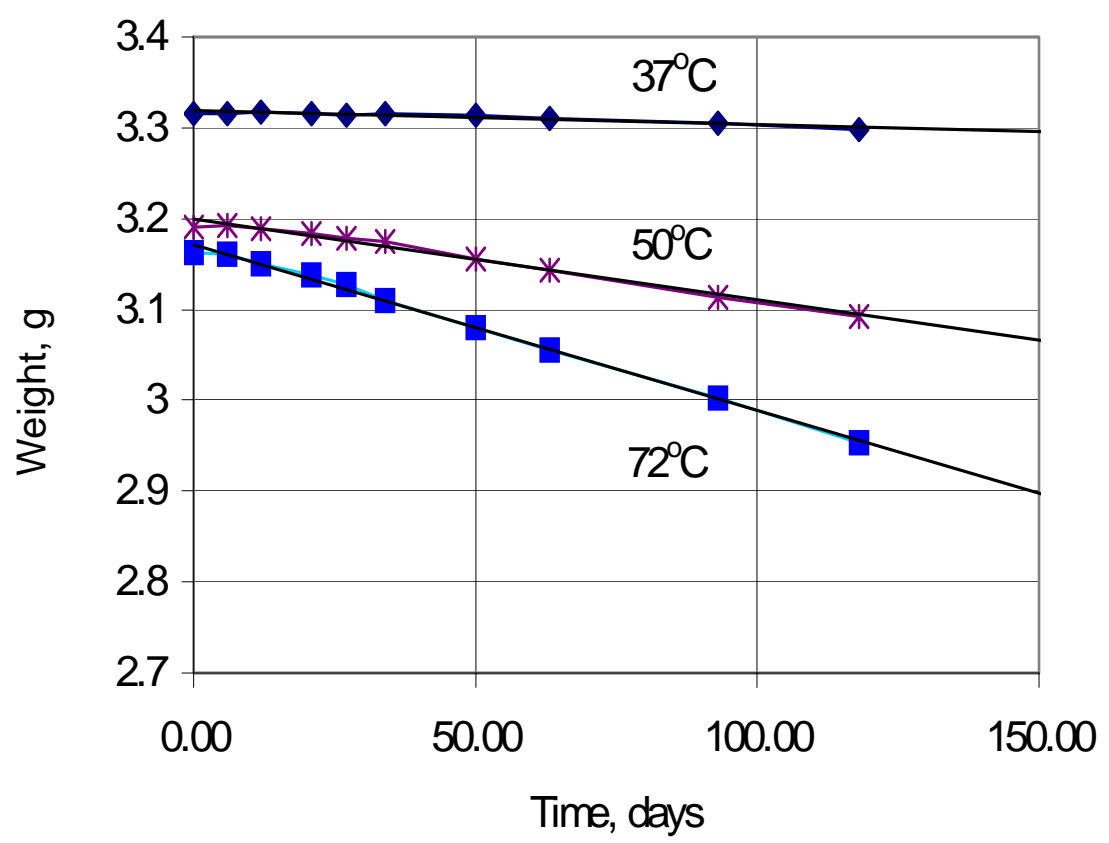

Figure 7. Solvent (EC/ EMC/PC/) weight loss in 15- $\mu \mathrm{m}$ nylon/ $25-\mu \mathrm{m} \mathrm{Al} / 50-\mu \mathrm{m}$ PP pouches over time as a function of temperature.

Several observations were made from these permeation results. All had similar water barrier behavior, as can be seen from an inspection of Figure 8a. This behavior is no surprise, since one of the primary goals of food and beverage packaging is to impede the transmission of water. Differences between the types of pouches did occur for those filled with solvents. The laminates that relied on either Surlyn or Forte Pi as the sealant layer had higher solvent loss rates than those that relied on PP, especially at elevated temperatures (Fig. 8b). Furthermore, pouches made with double $\mathrm{Al}$ foils ( $9 \mu \mathrm{m}$ each) faired slightly better than those made with a single layer of $25-\mu \mathrm{m}$ aluminum. Overall, the polypropylene with two layers of aluminum foil was the best solvent barrier in this first generation of laminates. Note, however, that even for this laminate material, its solvent permeation rate is still an order of magnitude higher than the water permeation rate.

A different approach was taken for analyzing the pouches filled with electrolyte. Several identical pouches were made of each laminate and placed in a 100\% humidity environment at the same three temperatures. The saturated water environment was maintained by using a setup similar to that in Figure 6, except with water under the false bottom. Periodically, one pouch would be cut open to extract the electrolyte within. This electrolyte was then titrated via Karl Fischer coulometric titration for water levels and burette titration for acid levels. The results at 

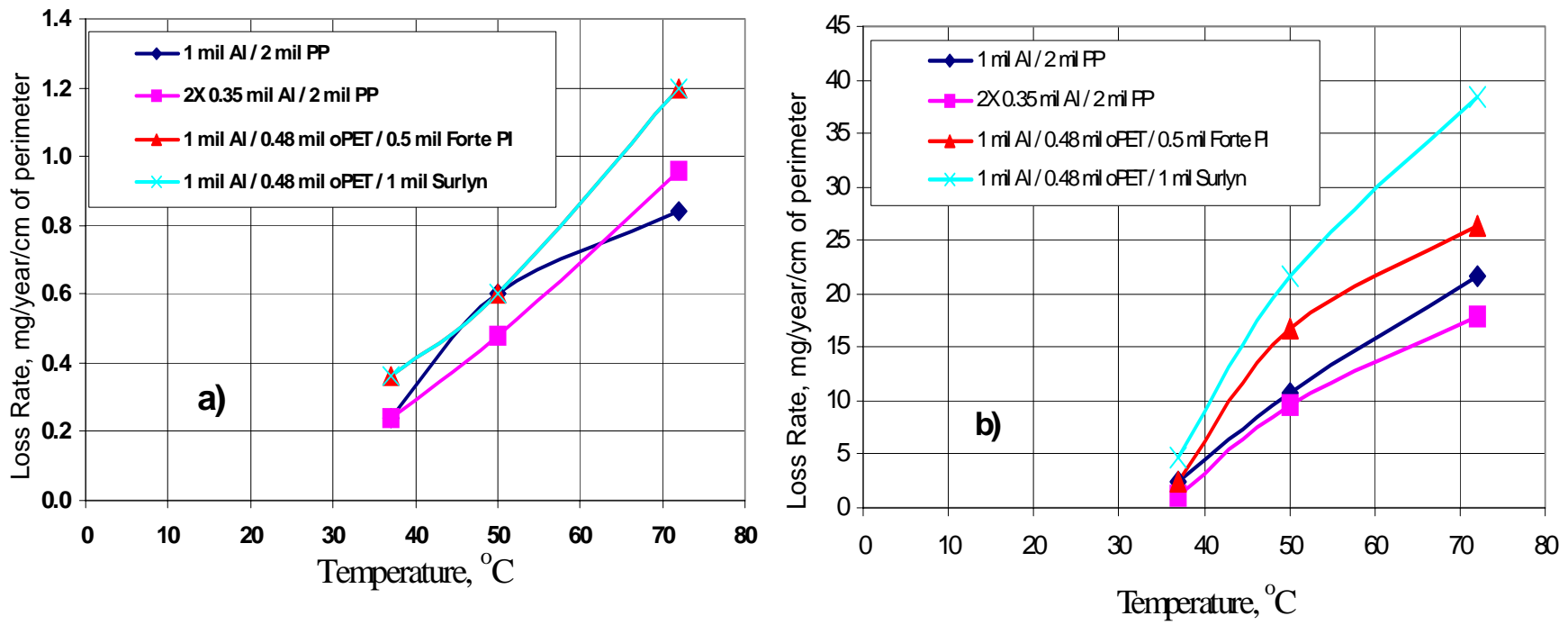

Figure 8. Summarized loss rates for first generation laminates obtained from pouch weight loss tests for (a) water inside and (b) EC/PC/EMC inside.

the two-week interval are presented in Figure 9. As expected, the acid levels (in units of ppm HF) were the lowest in the PP pouches. Many of the pouches ruptured within a few weeks due to the severity of the test conditions. The vast majority of the pouches that did survive beyond two weeks had PP as the sealant layer. In nearly all of the pouches, delamination was the primary cause of failure. This is discussed further in Appendix B.

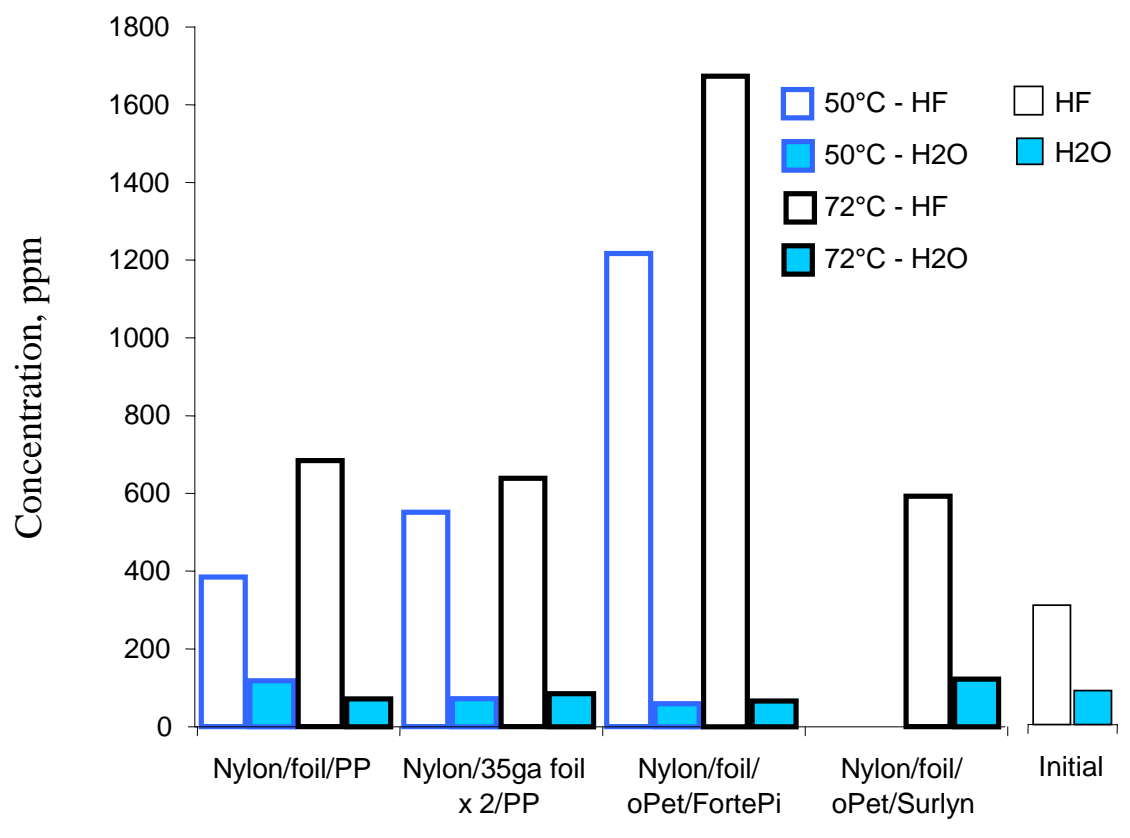

Figure 9. Water and HF concentration levels inside pouches filled with $1 \mathrm{M} \mathrm{LiPF}_{6}$ in EC/PC/DEC/EMC electrolyte after two weeks in a $100 \%$ humidity environment for first generation laminates. 
One of the laminates was submitted to Mocon to have quantitative film diffusion tests performed with electrolyte vapor in the same manner as the single films earlier. These results are included in Figure 5 so that a direct comparison can be made to the single films. At first glance, the permeation rate appears to be two orders of magnitude below that of the single films. However, upon extrapolation to room temperature, the laminate performed no better than most of the single films, most likely due to the assumption of Arrhenius behavior across the temperature span. As a result of this uncertainty, future tests were done at temperatures closer to ambient. Lowering the upper test temperature had the added effect of reducing the decomposition of $\mathrm{LiPF}_{6}$. It is surprising to find that there is any permeation through the laminate because of the 25$\mu \mathrm{m}$ aluminum foil. This suggests that there are still pinholes in the foil even at $25 \mu \mathrm{m}$ (a thickness at which the food packaging industry considers foil to be pinhole-free), or this represents the accuracy of the test apparatus.

\section{Moisture: Acid Relationship}

An anomaly was observed in the titration data in that the HF levels rose to significant levels while the water levels remained approximately constant (Figure 9). This was investigated further by intentionally doping one electrolyte sample with a known amount of water and another identical electrolyte sample with an amount of water ten times greater. Both samples underwent Karl Fischer and acid titration procedures over time. As expected, the acid concentrations rose in direct proportion to the amount of water added. However, the concentration of residual water decreased to approximately $500 \mathrm{ppm}$ in both samples (see Figure 10), which implies that the water was not fully consumed by reaction with the electrolyte salt. It is uncertain if this background moisture level is due to an equilibrium established with the electrolyte/HF or if it is an artifact of the Karl Fischer titration technique. Hence, one should not rely solely on moisture concentration levels in the long-term evaluation of their electrolyte integrity.
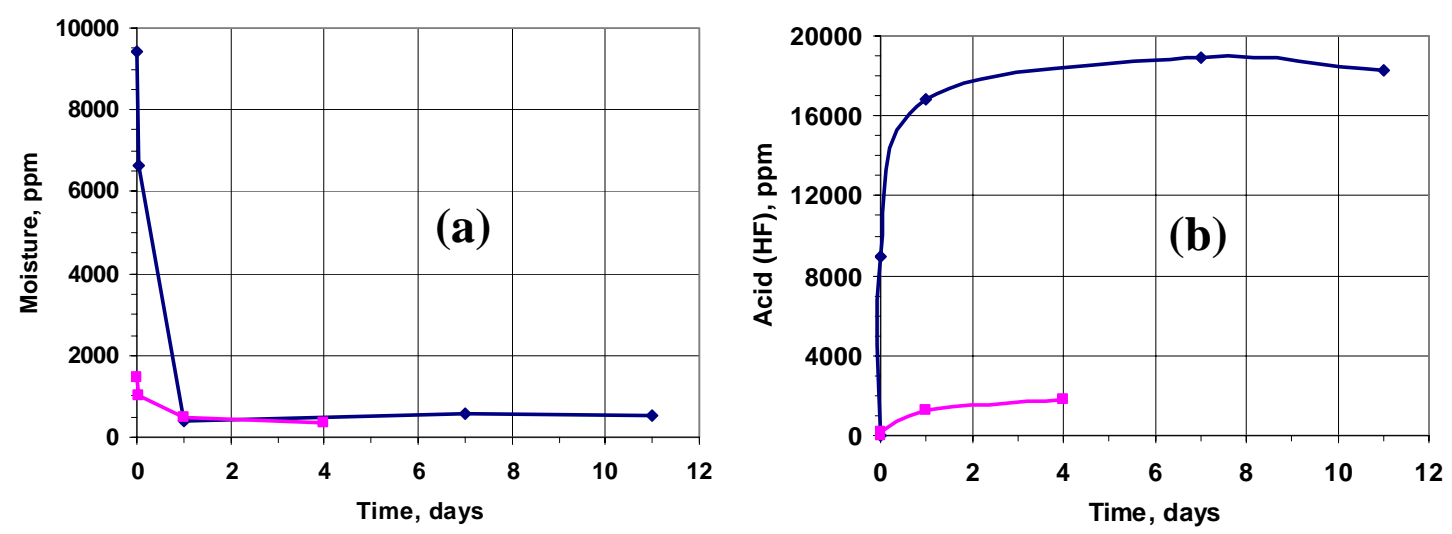

Figure 10. Moisture levels (a) and acid levels (b) resulting from intentional doping of electrolyte with 1,000 and 10,000 ppm of water. Note residual 500 ppm water.

It is well known that the electrolyte salt, $\mathrm{LiPF}_{6}$, decomposes in the presence of moisture. This is the main reason that the last step in cell assembly, electrolyte loading, is done in a dry glove box or dry room. The decomposition reaction is: 


$$
\mathrm{LiPF}_{6}+\mathrm{H}_{2} \mathrm{O} \Rightarrow \mathrm{LiF}+\mathrm{POF}_{3}+2 \mathrm{HF}
$$

Thus, one mole of water will result in the formation of two moles of HF. The data in Figure 10 were converted into molar units and, as expected, the ratio of change in water to change in HF was found to be 1:2 for both concentrations of water doping. As mentioned before, the surprising part was the residual levels of moisture. This suggests that the salt decomposition reaction listed above may not be irreversible as written, but rather, an equilibrium reaction.

\section{$\underline{\text { Screening of Moisture Adsorbents }}$}

A moisture adsorbent can be homogeneously mixed into any of the polymer layers or into the adhesive material. Numerous adsorbents are available, such as dehydrated magnesium phosphate, dehydrated manganese sulfate, activated alumina, silica gel, calcium sulfate (drierite), molecular sieves, clays, water-absorbent resins, and other salts capable of forming hydrates. The task is to find one that is suitable to use in lithium-ion electrolytes. Adsorbents should preferentially absorb moisture and not the electrolyte components, which would result in an electrolyte-starved cell.

Adsorbents were tested for moisture preference by exposing the dried adsorbents to saturated water vapor and then to saturated electrolyte solvent vapor while monitoring their weight change. Saturated environments were created by placement of an open vial of water (or solvent) alongside open vials of dried adsorbents, which were both placed inside a sealed mason jar. The test was then performed in reverse, i.e., the dried adsorbent was exposed to saturated electrolyte solvent vapor and then to saturated water vapor while monitoring their weight change. As an example, molecular sieves Type 3A, Type 4A, and Type 5A were found to preferentially absorb moisture over solvent as can be seen in Figure 11; whereas, Type 13X did not, which is why it finds great use in Protocol 2.1. Each of these molecular sieves was found to adsorb and retain equal amounts of moisture in the earlier "reverse" test (not shown). These sieves also have the desired property of readily reacting with HF acid.

Further tests were performed to see if the adsorbent material adversely reacted with the electrolyte salt. Molecular sieves may exchange their cation with the lithium cation of the electrolyte. The extent of this ion exchange was tested for Sieves 3A (K-based), 4A (Na-based), and 5A (Ca-based) by soaking $0.1 \mathrm{~g}$ of each sieve in $2.5 \mathrm{~mL}$ of LP40 electrolyte (EC/DEC) for 1 week in a glove box. Filtered samples of the electrolyte were analyzed for potassium, sodium, and calcium cations using inductively coupled plasma atomic emission spectroscopy (ICP-AES). The results of this analysis are shown in Table 3, which is a summary of the amount of lithium ions from the electrolyte that are exchanged with sodium, potassium, and calcium ions present in the molecular sieves. The fact that sodium cations were observed in the Type 3A and Type 5A sieves reflects the origin of these two sieves; they're made by ion exchanging with Type 4A sieve. These tests indicate that molecular sieve Type 5A would be an ideal absorbent. This finding was confirmed further by electrochemically cycling a lithium-ion flooded cell in direct contact with ample amounts of Type 5A sieve for more than 1100 cycles. 


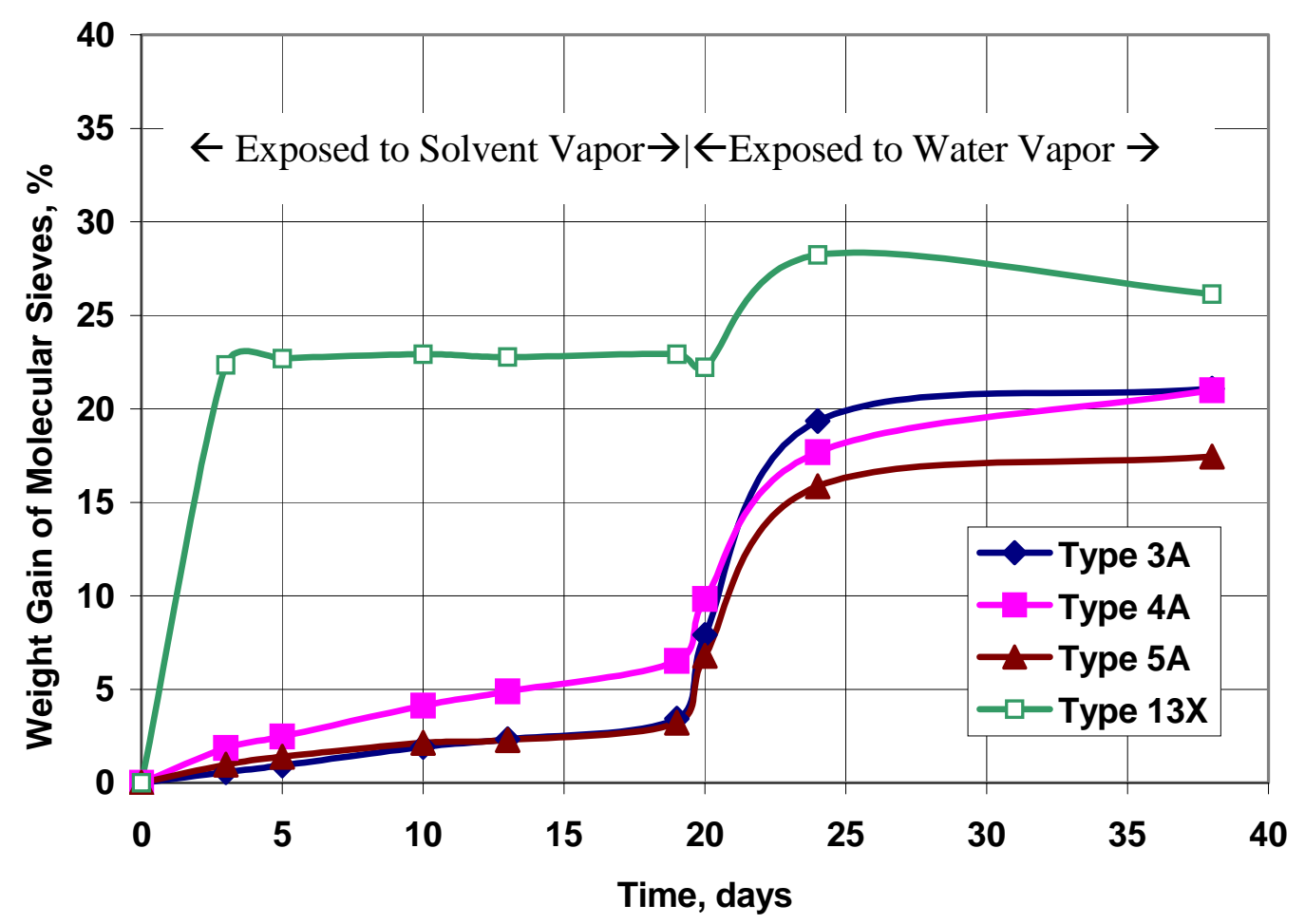

Figure 11. Weight gain of various molecular sieves exposed to DEC solvent followed by exposure to moisture after 19 days as a percent of dry weight.

Table 3. Milligrams of cation exchanged by lithium per gram of molecular sieve.

\begin{tabular}{|c|c|c|c|}
\hline Molecular Sieve & Sodium & Potassium & Calcium \\
\hline Type 3A & 20.1 & 27.8 & $<0.03$ \\
\hline Type 4A & 57.4 & $<0.5$ & $<0.03$ \\
\hline Type 5A & 4.1 & $<0.5$ & $<0.03$ \\
\hline
\end{tabular}

\section{Pressure Tests of Seals}

The seal strength of each of the types of laminates was tested by heat-sealing three sides of a pouch and then clamping the fourth unsealed side with a rubber gasket inserted between the laminates. The rubber gasket was fitted with a gas nozzle and pressure was increased until the pouch ruptured. Generally, the pouch ruptured along the face and not the seam. The face strength of the laminate layer was tested by sandwiching a single sheet of the laminate between two annular gaskets, applying a gas fitting, and increasing the gas pressure until the sheet ruptured. The most important observation that can be made from these tests was that the pouches and laminates made with polyester were consistently stronger than all of the others. This was to be expected in light of Table 2. 


\section{APPENDIX B: LAMINATION RESULTS}

After analyzing the failure mechanism of the first generation of pouches, it was found that nearly all of the electrolyte-filled pouches (and some of the solvent-filled) suffered from delamination of the interior barrier film(s) from the $\mathrm{Al}$ foil. It had been assumed that the layer of aluminum foil would provide an impenetrable layer to moisture, electrolyte (solvents), HF, and nearly everything else. Once delamination occurs, solvents can then permeate across the thin face of the pouch rather than through the relatively long seal width at the edge of the pouch. Such delamination would increase the area available for permeation by a factor of 1000 for a 10-Ah cell. Naturally, efforts were directed to identifying better adhesives (see Reference 7 for a general description of adhesives).

A common misperception often exists that the foil interface does not experience exposure to electrolyte, especially if an additional interior layer of polyester is adhered between the sealant layer and the aluminum foil layer. This can easily be disproved through a simple Fickiandiffusion differential equation; $(\partial \mathrm{c} / \partial \mathrm{t})=\mathrm{D} \cdot\left(\partial^{2} \mathrm{c} / \partial^{2} \mathrm{x}\right)$, where $\mathrm{c}$ is the solvent concentration, $\mathrm{D}$ is the solvent diffusion coefficient, and $\mathrm{x}$ is the distance perpendicular to the film face. The solution to this equation can be found in many mass transport textbooks (see for example, Reference 8). The concentration of the solvent is known, the film thickness is typically 50 microns, and the time duration is 15 years. From the solution to this equation, the diffusion coefficient would have to be on the order of $10^{-15} \mathrm{~cm}^{2} / \mathrm{s}$ to prevent the electrolyte solvent from contacting the aluminum foil. Tabulated literature values do not exist for carbonate solvents, but do exist for common polar solvents in various polymers [4]. In general, they vary from $10^{-9}$ to $10^{-7} \mathrm{~cm}^{2} / \mathrm{s}$. It is highly unlikely that diffusion coefficients of carbonate solvents would be 10 million times smaller than other common polar solvents. Note, however, that in true solid polymer electrolytes, the diffusion coefficient for polymer solvents (such as polyethylene oxide) diffusing in the sealant layer may indeed be orders of magnitude smaller than for liquid solvents.

\section{$\underline{\text { Solvent Cast and Two-Part Industrial Adhesives }}$}

Rollprint was able to send ANL several commercial solvent-cast adhesive samples applied to Al pans. Additional solvent-cast and two-part adhesives were obtained from vendors and applied to aluminum foil. Test strips were cut from these adhesive samples and soaked in electrolyte at $55^{\circ} \mathrm{C}$ in Nalgene bottles to test their electrolyte compatibility. These sample bottles were placed in an oven exposed to ambient air. Moisture in the air slowly permeates into the Nalgene bottles at this temperature and turns the electrolyte brown over time. This is an aggressive test due to the acid formation and the edge attack of the interface between the aluminum foil and the adhesive. It does suffer from a lack of acid and moisture control of the electrolyte but it is a quick useful way to screen through numerous samples. Later coupon tests were done in an incubator at $55^{\circ} \mathrm{C}$ inside an inert atmosphere glove box for samples that passed this early screen.

Results of these coupon soak tests are presented in Table 4. Common observations made include swelling of the adhesive, delamination from the Al foil, tackiness, gelling, and dissolving. In general, the adhesive that remained whole delaminated, while the ones that remained tacky dissolved at elevated temperatures. An ideal solvent-cast adhesive has not been found to date that 
can withstand the aggressiveness of the electrolyte used in typical lithium-ion cells. This is not too much of a surprise considering the polar nature of the electrolyte.

While the solvent cast adhesives may not be appropriate for the interfaces on the electrolyte side of the aluminum foil, they should find use on the exterior side of the foil. They are commonly used to laminate polyester and nylon to foil, materials that do not readily bond through co-extrusion. The Adcote 506-40 or the Loctite adhesive may find use in this application. Some interesting results were obtained for Cotronic's two-part epoxies, Duralco 4538, which is a flexible epoxy and Duralco 4461, which is a hard epoxy. The 4461 was not affected by the electrolyte, but was unfortunately too brittle. The 4538 was very flexible but it swelled and delaminated. Cotronics does offer flexibilizers that may be added to the Duralco 4461 and should be considered.

Table 4. Solvent cast and two-part industrial adhesives cast on aluminum foil and soaked in electrolyte (1 $\mathrm{M} \mathrm{LiPF}_{6}$ in EC/DEC/DMC/EMC/PC) at $55^{\circ} \mathrm{C}$ for 1 day.

\begin{tabular}{|l|l|l|}
\hline \multicolumn{1}{|c|}{ Adhesive } & \multicolumn{1}{c|}{ Manufacturer } & \multicolumn{1}{c|}{ Results } \\
\hline Adcote 503A + Coreactant F & Rohm \& Haas & Delaminated, swelled \\
\hline \hline Adcote 503E + Coreactant F & Rohm \& Haas & Delaminated, swelled \\
\hline Adcote 506-40 + Coreactant F & Rohm \& Haas & Partially dissolved \\
\hline \hline Adcote 555 + Coreactant 536B & Rohm \& Haas & Delaminated, swelled \\
\hline \hline Robond L2150 + Aqua-Lam 9X101 & Rohm \& Haas & Delaminated, swelled \\
\hline Duralco 4538 & Cotronics & Delaminated, swelled \\
\hline \hline Duralco 4461 & Cotronics & Not affected, brittle \\
\hline Prism 401 & Loctite Corp. & Partially dissolved \\
\hline Prism 411 & Loctite Corp. & Partially dissolved \\
\hline
\end{tabular}

$\underline{\text { Hot-Melt and Tie-Layer Adhesives }}$

Hot-melt and tie-layer adhesives are typically applied by melting, as is done in coextrusion processes. The difference in terminology is often a matter of semantics because they are all generally low-melting thermoplastics. They were applied to aluminum foil, cut into test coupons, and immersed in electrolyte at $55^{\circ} \mathrm{C}$ in the same manner as the solvent-cast adhesives above. Generic films of PE, PP, EVOH, and Surlyn (Zn) were melted onto aluminum foil and tested in the same manner to establish a reference point. Results of these tests are listed in Tables 5 and 6. The best results were obtained for Rohm and Haas's Tymor family of tie-layer adhesives, which are acid-modified polyolefins (PE and PP). These materials could be blended with polyolefins and coextruded onto aluminum foil and would serve as the sealant and adhesive layer combined, an ideal situation. As expected, the pure films of polyethylene and polypropylene delaminated because they lack functional groups that grab onto the aluminum surface. EVOH also shows good signs of adhesion to aluminum; unfortunately, it tends to 
become brittle upon soaking in electrolyte and is prone to moisture absorption. Surlyn, especially the zinc ionomers, also has good adhesion properties and can find use in certain laminate designs. (The sodium ionomers delaminated much sooner.) However, it deforms easily at low temperatures $\left(\sim 70^{\circ} \mathrm{C}\right)$ and, thus, may find limited use as a sealant layer. The results in this study are meant only for guidance and could easily vary depending on the application conditions; please consult with an industrial representative from each company to better tailor usage.

Table 5. Hot-melt industrial adhesives (and PP and PE for reference) cast on aluminum foil and soaked in electrolyte (1 $\mathrm{M} \mathrm{LiPF}_{6}$ in EC/DEC/DMC/EMC/PC) at $55^{\circ} \mathrm{C}$ for 1 day.

\begin{tabular}{|l|l|l|}
\hline \multicolumn{1}{|c|}{ Adhesive } & \multicolumn{1}{c|}{ Manufacturer } & \multicolumn{1}{c|}{ Results } \\
\hline HL 6400 & H.B. Fuller & Completely dissolved \\
\hline HL 6369 & H.B. Fuller & Completely dissolved \\
\hline BLOX 4000 & Dow Plastics & Delaminated, swelled \\
\hline BLOX 0000 & Dow Plastics & Delaminated, gelled \\
\hline Hysol 7811 & Loctite Corp. & Completely dissolved \\
\hline Low Density Polyethylene & (generic) & Delaminated \\
\hline Polypropylene & (generic) & Delaminated \\
\hline
\end{tabular}

Table 6. Tie-layer industrial adhesives cast on aluminum foil and soaked in electrolyte (1 $\mathrm{M} \mathrm{LiPF}_{6}$ in $\mathrm{EC} / \mathrm{DEC} / \mathrm{DMC} / \mathrm{EMC} / \mathrm{PC}$ ) at $55^{\circ} \mathrm{C}$ for 1 day.

\begin{tabular}{|l|l||l|}
\hline \multicolumn{1}{|c|}{ Adhesive } & \multicolumn{1}{|c|}{ Manufacturer } & \multicolumn{1}{c|}{ Results } \\
\hline EVOH & EVAL Co. & Held tight \\
\hline Surlyn & Dupont Co. & Held tight \\
\hline Tymor 1N05 (Modified Polyolefin) & Rohm \& Haas & Held tight \\
\hline Tymor 1221E (PE-based) & Rohm \& Haas & Held tight \\
\hline Tymor 1258B (PE-based) & Rohm \& Haas & Peel with great force \\
\hline Tymor 2216 (PP-based) & Rohm \& Haas & Peel with moderate force \\
\hline $\begin{array}{c}\text { Admer QF551A (anhydride modified } \\
\text { copolymer PP-based) }\end{array}$ & Mitsui Chem. & Peel with moderate force \\
\hline Primacor 5980I (ethylene acrylic acid) & DOW Chemical & Peel with moderate force \\
\hline \hline Primacor 3340 (ethylene acrylic acid) & DOW Chemical & Peel with slight force \\
\hline \hline Primacor 3440 (ethylene acrylic acid) & DOW Chemical & Peel with slight force \\
\hline \hline Eastobond Copolyester 19411 & Eastman Chem. & Peel with slight force \\
\hline $\begin{array}{c}\text { EMAC SP2220 (ethylene-methyl } \\
\text { acrylate copolymer) }\end{array}$ & Voridian (Eastman) & Completely delaminated \\
\hline
\end{tabular}




\section{Long-Term Study of Candidate Adhesives in Dry Electrolyte}

Several candidate materials listed in Table 6 were subjected to a better-controlled electrolyte soak test. Test coupons were made as before and soaked in electrolyte blend $(1 \mathrm{M}$ $\mathrm{LiPF}_{6}$ in EC/DEC/DMC/EMC/PC) in Nalgene bottles, except this time the bottles were stored in an incubator at $55^{\circ} \mathrm{C}$ inside an inert atmosphere glove box. This test would better approximate the conditions inside a cell container. Results are presented in Table 7. The best performing materials are highlighted in blue. A test strip from Sumitomo Electric Industries' (SEI) laminate was included in this study to establish a baseline. As can be seen from this table, the best materials are the Surlyn zinc ionomers and EVOH LC-L101A. The laminate from SEI performed exceptionally well, too. Again, the results in this study are meant only for guidance and could easily vary depending on the application conditions.

Table 7. Candidate industrial adhesives cast on aluminum foil and soaked in electrolyte (1 $\mathrm{M} \mathrm{LiPF}_{6}$ in EC/DEC/DMC/EMC/PC) at $55^{\circ} \mathrm{C}$ in inert glove box.

\begin{tabular}{|l|l|l|}
\hline Adhesive & Manufacturer & Time to delamination, color \\
\hline Tymor 1N05 (Mod. Polyolefin) & Rohm \& Haas & 2 weeks, colorless \\
\hline Tymor 1221E (PE-based) & Rohm \& Haas & 4 weeks, colorless \\
\hline Tymor 1258B (PE-based) & Rohm \& Haas & 6 weeks, colorless \\
\hline EVOH LC-E105B & EVAL Co. & $\sim 10$ weeks, tan \\
\hline EVOH LC-E105B \& clay & EVAL/ANL & $\sim 15$ weeks, black \\
\hline EVOH EP-F104BW & EVAL Co. & $\sim 20$ weeks, light beige \\
\hline EVOH LC-L101A & EVAL Co. & $\sim 45$ weeks, light beige \\
\hline EVOH GC-156B & EVAL Co. & $\sim 15$ weeks, bronze \\
\hline Surlyn 1652 (Zn ionomers) & DuPont & $>49$ weeks, colorless \\
\hline Surlyn 1801 (Zn ionomers) & DuPont & $>49$ weeks, colorless \\
\hline SEI Laminate from 12/01 & Sumitomo & $>49$ weeks, colorless \\
\hline
\end{tabular}

\section{Pretreatment of Aluminum Foil}

Another method of attaching the sealant layer onto the aluminum foil is to use pretreatments on the aluminum surface. Pretreatments work by modifying the oxide coating on the aluminum to a morphology that is conducive to polymer bonding. The best-known pretreatment uses hexavalent chromium such as in Henkel's Alodine 1200 solution, to prepare aluminum surfaces on ships and planes for painting. These $\mathrm{Cr}^{6+}$ processes are being phased out due to their environmental toxicity. New solutions are being actively pursued, with strong support coming from several defense programs. 
Several vendors were contacted for samples of their pretreatment solutions and recommendations. These solutions were applied to aluminum foil, dried according to instructions, and then polypropylene sheets were melted onto them. Test strips were cut from these laminates and soaked in electrolyte at $55^{\circ} \mathrm{C}$ in Nalgene bottles in an oven exposed to ambient air. These industrial pretreatments are described in Table 8. One of these pretreatments performed exceptionally well. The polypropylene film held to the Alodine 5200 treated aluminum foil (highlighted in Table 8) for more than 41 weeks. Note that this is in an airexposed oven. All other pretreatments failed within a few days. Again, the results in this study are meant only as guidance; many new pretreatments are still under development commercially.

Table 8. Polypropylene adhesion to pretreatments applied to aluminum foil and soaked in electrolyte (1 $\mathrm{M} \mathrm{LiPF}_{6}$ in EC/DEC/DMC/EMC/PC) at $55^{\circ} \mathrm{C}$.

\begin{tabular}{|l|l|l|}
\hline \multicolumn{1}{|c|}{ Pretreatment } & \multicolumn{1}{c|}{ Manufacturer } & \multicolumn{1}{c|}{ Comments } \\
\hline Alodine 5200 & Henkel Surface Tech. & Ti-based fluororefractory \\
\hline Z-100 & Dovey Corp. (Natural Coating Sys.) & Zirconia based \\
\hline Z-168 & Dovey Corp. (Natural Coating Sys.) & Zirconia based \\
\hline Oxsilane AL-0500 & Chemetall Oakite (Brent Chemcoat) & Silane-based,fluotitanic acid \\
\hline Oxsilane MM-0705 & Chemetall Oakite (Brent Chemcoat) & Silane-based \\
\hline Gardobond X 4591 & Chemetall Oakite (Brent Chemcoat) & Zirconium, fluoride based \\
\hline Gardobond X 4650 & Chemetall Oakite (Brent Chemcoat) & Zirconium, fluoride based \\
\hline Prekote (X-IT) & Pantheon Chemical & $\begin{array}{l}\text { Biodegradable, polar/non- } \\
\text { polar molecule }\end{array}$ \\
\hline
\end{tabular}




\section{APPENDIX C: FEED-THROUGH DESIGN CRITERIA}

Lamination of the sealant film to the aluminum foil is the linchpin to attaining a calendar life of 15 years. It will also form the basis for sealing the metal feed-throughs between the two laminate sheets that compose the pouch. The problem of sealing the feed-throughs to the pouch is very similar to that of adhering the sealant layer to the aluminum foil. In essence, the feedthrough is just a metal that must be attached to a sealant material just like the aluminum foil is attached to the sealant layer, only the dimensions (and perhaps metal) are different.

This task has additional challenges as well. The most important is in hermetically sealing/adhereing the three-dimensional leads in between the two-dimensional sealant films without electrically contacting the aluminum foil within the laminate. Other areas of concern were identified that must be addressed for a successful design: the voltage drop down the length of the feed-through; the temperature rise in the feedthrough; and delamination, or separation, of the feedthrough from the laminate. It is hoped that the delamination challenge will become less daunting once appropriate sealant films and adhesives are fully developed. Just as in the bonding of aluminum foil to the sealant layer, an adhesive wrap, a corona discharge treatment, or a metal pretreatment will be the critical step.
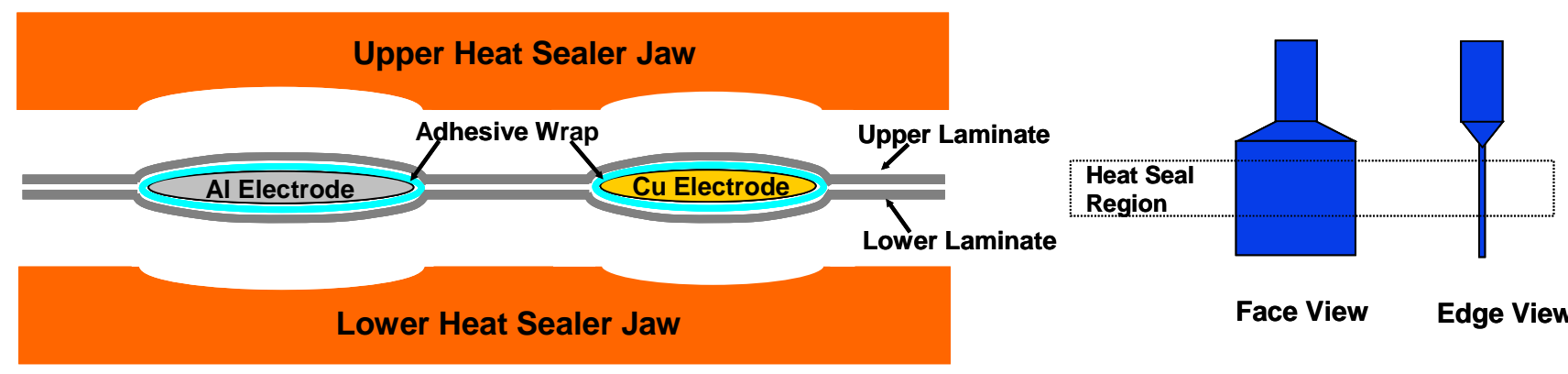

Face View

Edge View

Figure 12. Feed-through design that minimizes circumference of electrodes and minimizes distortion of laminate face. The adhesive wrap is the critical component.

\section{Temperature Rise in Feed-Through}

A simple Excel spreadsheet program was written to explore the voltage drop and temperature rise in the feed-through under the most severe condition, which is during the 18-sec pulse. For a battery pack that consists of 48 cells at $3.5 \mathrm{~V}$ each, a $25-\mathrm{kW}$ pulse would imply that a 149 amp current is flowing through each feed-through. In the spreadsheet it was further assumed that one feed-through was copper and the other aluminum, each feed-through is $5 \mathrm{~cm}$ long, the resistance of each lead would be equal, and the combined voltage drop due to the two feed-throughs would be $0.5 \%$ of the cell voltage $(18 \mathrm{mV})$. These parameters, as well as the type of metal, can be varied in the spreadsheet.

The results of the model indicate that the aluminum feed-through would need a crosssectional area of at least $0.24 \mathrm{~cm}^{2}$ and the copper would need at least $0.15-\mathrm{cm}^{2}$ cross-sectional area. The actual feed-through would most likely be a rectangular bar with either rounded edges 
or an elliptic shape to prevent tearing of the laminate sheet, as in Figure 12. The bar must not be too thick as this would distort the face of the pouch and be difficult to seal; a thickness of $1 \mathrm{~mm}$ would be appropriate. Thus, the aluminum feed-through would be approximately $1 \mathrm{~mm} \mathrm{x}$ $24 \mathrm{~mm}$ and the copper would be approximately $1 \mathrm{~mm}$ x $15 \mathrm{~mm}$.

The temperature rise due to resistive heating $\left(\mathrm{I}^{2} \mathrm{R}\right)$ that occurs as a result of the briefduration 18-second pulse can be assumed to be adiabatic. This conservative assumption essentially means that the heat cannot be dissipated readily during the brief duration of the current pulse. Under such conditions, the temperature rise is $8.0^{\circ} \mathrm{C}$ in the aluminum feedthrough and $9.3^{\circ} \mathrm{C}$ in the copper feed-through. These temperature rises are not insignificant, but they are manageable. If the feed-through is undersized, and the current pulse is excessive in magnitude or duration, it is possible that the feed-through could heat to the point where the sealant film melts, causing the pouch to rupture. Keep in mind that the feed-through is also partially responsible for conducting the heat generated by the cell out to the thermal management system. This spreadsheet model shows that it is probably more important to design the feedthrough to maximize thermal conduction rather than just minimize the IR voltage loss.

\section{Bonding to Copper}

A concern may exist regarding the interface between polymers and non-aluminum metals such as copper. Copper is the metal current collector for the graphite electrode in lithium-ion batteries. However, copper may behave as a catalyst to promote oxidative decomposition of olefinic polymers. In general, the oxidative power of metal catalyst in polymers is, in decreasing order: $\mathrm{Co} \rightarrow \mathrm{Mn} \rightarrow \mathrm{Cu} \rightarrow \mathrm{Fe} \rightarrow \mathrm{V} \rightarrow \mathrm{Ni} \rightarrow \mathrm{Ti} \rightarrow \mathrm{Al} \rightarrow \mathrm{Mg} \rightarrow \mathrm{Ba}$. More can be read about this in Reference 9. A method of overcoming this problem is cladding or plating of the copper with a less catalytic metal, such as nickel.

\section{Dielectric Breakdown of Packaging}

In their pure form, most polymer materials have great electrical insulating properties. This fact is often relied upon in the electrical and appliance industry, but should not be taken for granted in the HEV battery application. Many of these batteries are designed with operating voltages greater than 300 volts. Polyolefin materials can withstand this voltage if they are thick enough; polypropylene is often used to insulate common wiring. The thickness of interest is not the distance between the positive and negative feed-throughs, but rather, the distance between each feed-through and the metal foil substrate in the packaging laminate. This distance is often only 50 microns. A short between one electrode and the laminate foil would electrify the whole foil, which could then short to the other electrode. The developer may be wise to include a protective insulating strip around the feed-throughs in the heat-seal region. Keep in mind especially that moisture adsorbents in the sealant layer may interfere with the insulating property of the sealant layer. Electrical breakdown tests should be performed on each complete pouch assembly (feed-throughs sealed between laminate sheets) to establish their voltage limits. 


\section{APPENDIX D: TESTING OF SUMITOMO ELECTRIC INDUSTRY'S POUCHES}

Sumitomo Electric Flat Components, Inc. (now a subsidiary of Sumitomo Electric Industries, LTD., or SEI) has been developing and marketing flexible laminates to the lithiumion battery industry for the last several years. Argonne National Laboratory (ANL) and SEI have had numerous interactions regarding flexible packaging for HEV batteries since the start of this project. In the summer of 2002, SEI displayed to ANL a relatively large size flexible pouch that the company was in the process of marketing. The dimensions of this pouch are very near to that required in a HEV-sized cell. At this meeting, a test matrix was outlined that would test the pouch's survival under the harsh conditions expected in an HEV battery. Thermal cycling and hot, humid storage were of primary interest. SEI agreed to fabricate $30 \mathrm{HEV-sized} \mathrm{pouches,} \mathrm{each}$ with one $\mathrm{Al}$ electrode feed-through and one $\mathrm{Ni}$-coated $\mathrm{Cu}$ electrode feed-through, and filled with $50 \mathrm{~g}$ of $1.2 \mathrm{M} \mathrm{LiPF}_{6}$ in a blend of EC:DEC:DMC:EMC:PC (see Figure 13). There were no electrodes or active materials in these pouches. The pouches were then shipped to ANL to undergo accelerated thermal-aging profiles to test their thermal abuse response.

Figure 13. HEV-sized pouch from SEI with feed-throughs and electrolyte.

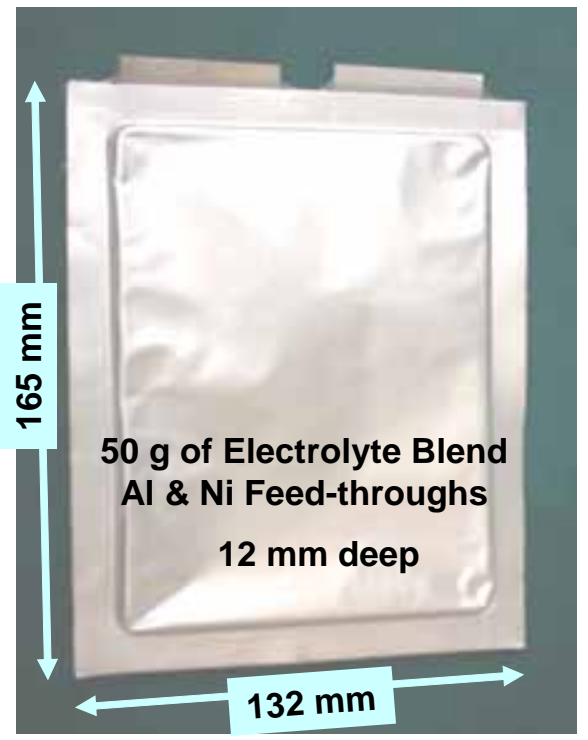

Thermal Abuse Test Plan

Thirteen of these HEV-sized pouches were stored at $55^{\circ} \mathrm{C}$ and $\sim 83 \%$ relative humidity (RH). The relative humidity was maintained by stacking the pouches in a sealed plastic container alongside a saturated aqueous solution of potassium nitrate in glass beakers (see Figure 14). Ten pouches underwent rapid thermal cycling between $-40^{\circ} \mathrm{C}$ and $60^{\circ} \mathrm{C}$, and seven underwent summer/winter thermal cycling as shown in Figures 15 and 16, respectively. The summer/winter thermal profile is intended to mimic the effects of changes in season. Summer months are represented by 265 consecutive thermal cycles between $20^{\circ} \mathrm{C}$ and $60^{\circ} \mathrm{C}$ at $\sim 90 \% \mathrm{RH}$. This is followed by winter months, which are represented as 100 consecutive thermal cycles between $-40^{\circ} \mathrm{C}$ and $20^{\circ} \mathrm{C}$ at ambient humidity (no humidity control inside the chamber). This 365-cycle sequence was repeated throughout the duration of the test schedule. The weight and integrity of these 30 pouches were monitored and periodically one was opened and analyzed for $\mathrm{HF}, \mathrm{H}_{2} \mathrm{O}$, and solvent degradation. 
During early shakedown experiments, water droplets were observed on pouches that cycled below $0^{\circ} \mathrm{C}$ in a 95\% $\mathrm{RH}$ environment. Concern existed that the water droplets near the seam would create an unrealistic and extreme test condition; pouches might fail prematurely before meaningful data could be collected. It was decided that the pouches that undergo the rapid thermal cycling and the winter thermal cycling would be removed from the sealed relative humidity container and instead rely on ambient humidity only. This also had the added benefit of increasing the thermal ramp rates because the pouches were now exposed directly to the forced air convection of the chamber. When the pouches underwent the summer thermal cycling, they were returned to the sealed container with the saturated aqueous solution of potassium nitrate.

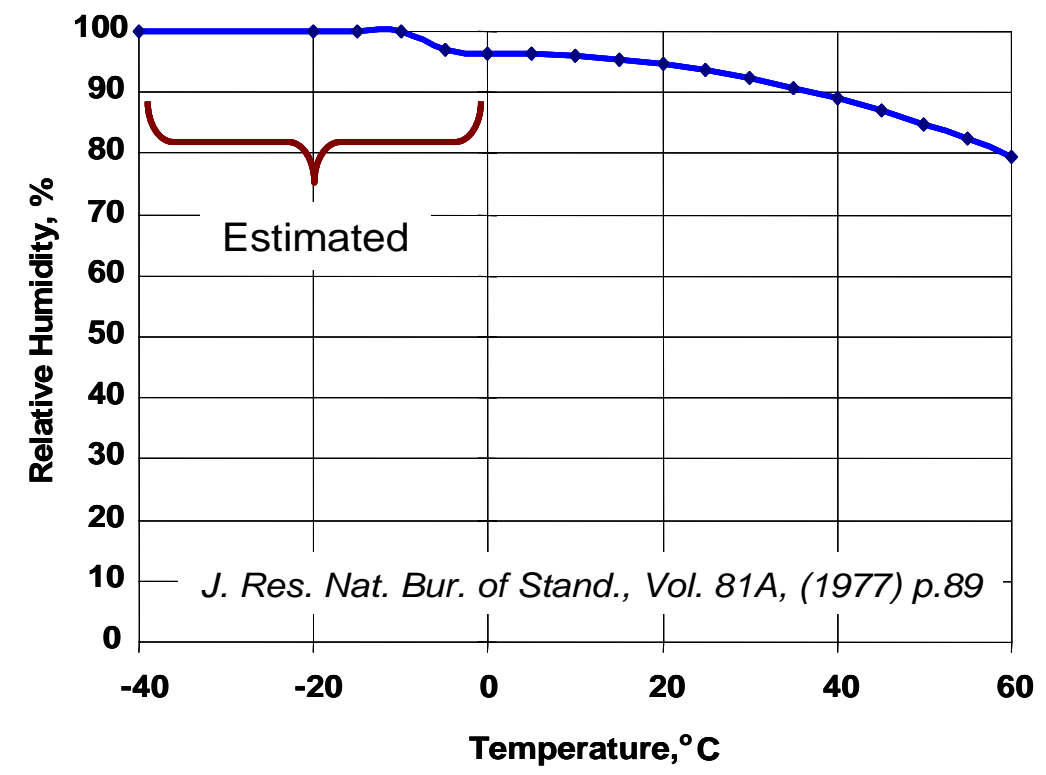

Figure 14. Humidity control using saturated aqueous solution of potassium nitrate [10].
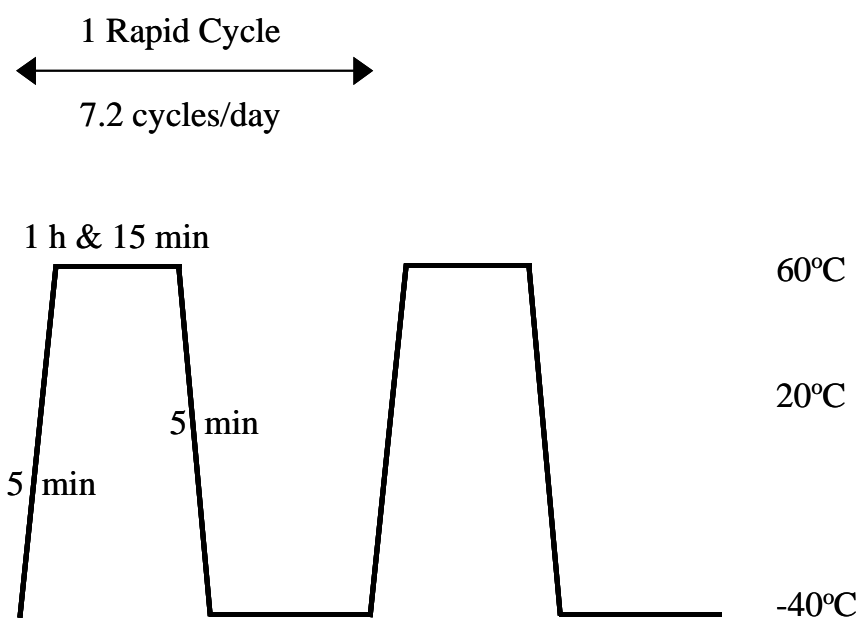

$1 \mathrm{~h} \& 55 \mathrm{~min}$

Figure 15. Programmed temperature profile used for rapid thermal cycling between -40 and $60^{\circ} \mathrm{C}$ in a Tenney Jr. temperature chamber under ambient humidity. 

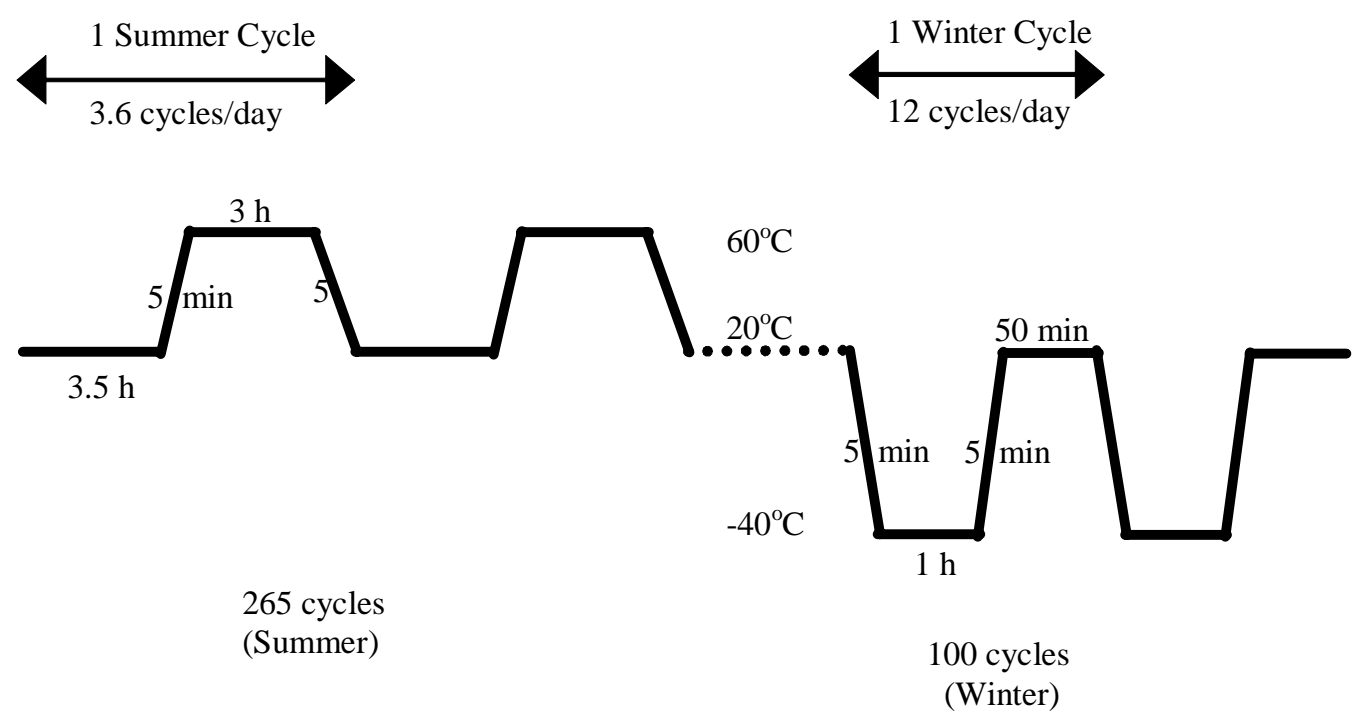

Figure 16. Programmed temperature profiles for summer/winter thermal cycling in a Tenney Jr. temperature chamber. The summer thermal cycle is the only cycle performed in a sealed plastic container at $\sim 90 \% \mathrm{RH}$.

\section{Meausurement of Thermal Lag Inside Pouches}

A special HEV-sized pouch was made to determine the actual temperature reached inside the SEI pouches during the various thermal profiles. This pouch was fabricated from SEI laminate stock at ANL with $55 \mathrm{~g}$ of electrolyte blend inside and an RTD probe inserted into the pouch that was sealed with EVOH. The probe was inserted to a depth such that its tip was in the bulk of the electrolyte to get an accurate measurement of the true electrolyte temperature. Each thermal cycle was performed with this pouch placed in the middle of the other pouches. The pouch electrolyte temperature and the chamber temperature were recorded simultaneously by hand. There was a large thermal lag created by the RH container setup in the case of the summer profile (Figure 17). Profiles that did not use the RH container were much faster (Figure 18). The profiles were adjusted according to these results to guarantee that the pouch seals truly reach the temperature set points (Figures 15 and 16). This is an important issue that battery developers must consider when performing thermal cycling survival tests. 


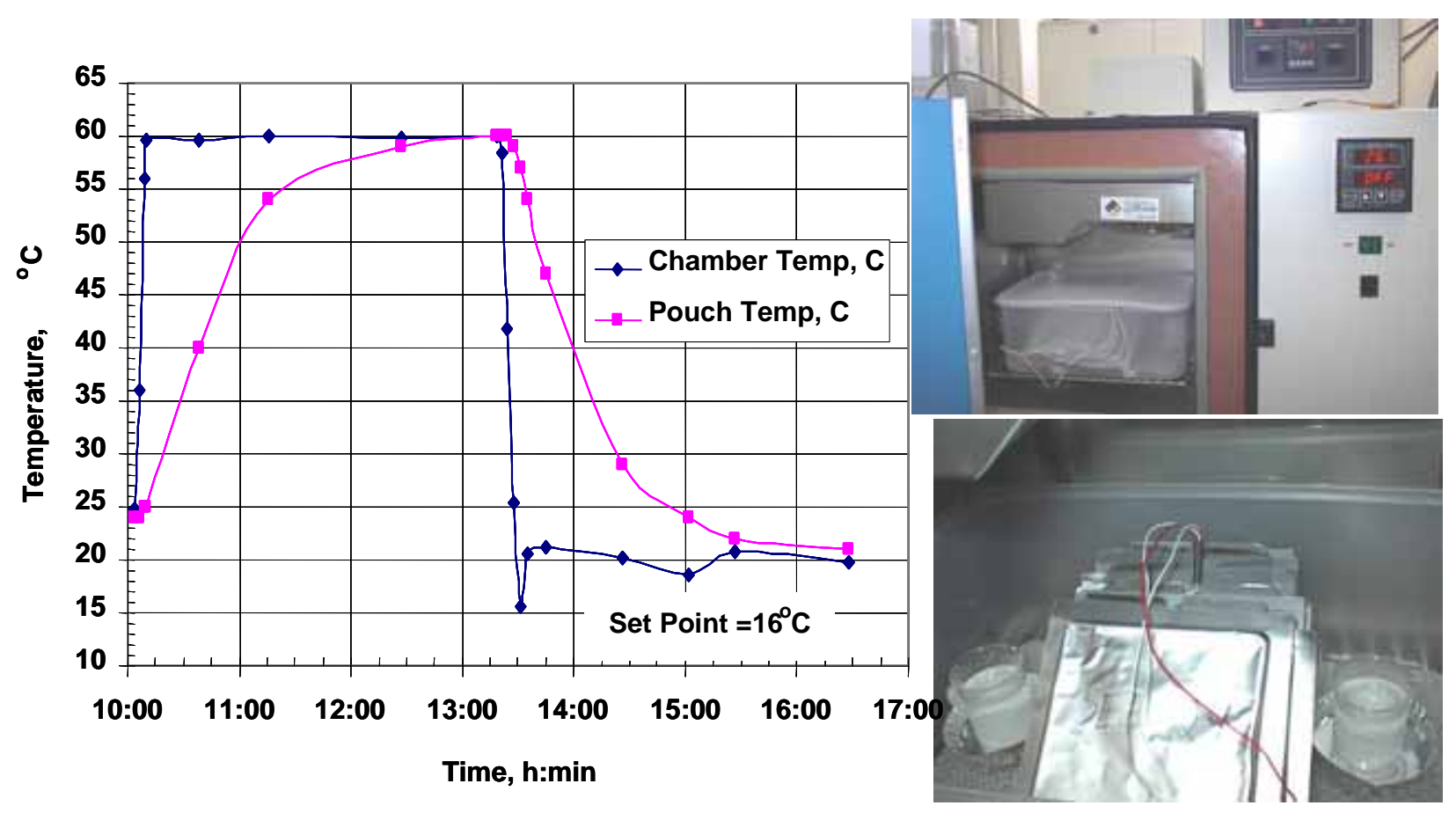

Figure 17. Temperature measurements inside pouch electrolyte and in Tenney Jr. temperature chamber for summer thermal cycling in a sealed plastic container at $\sim 90 \% \mathrm{RH}$.

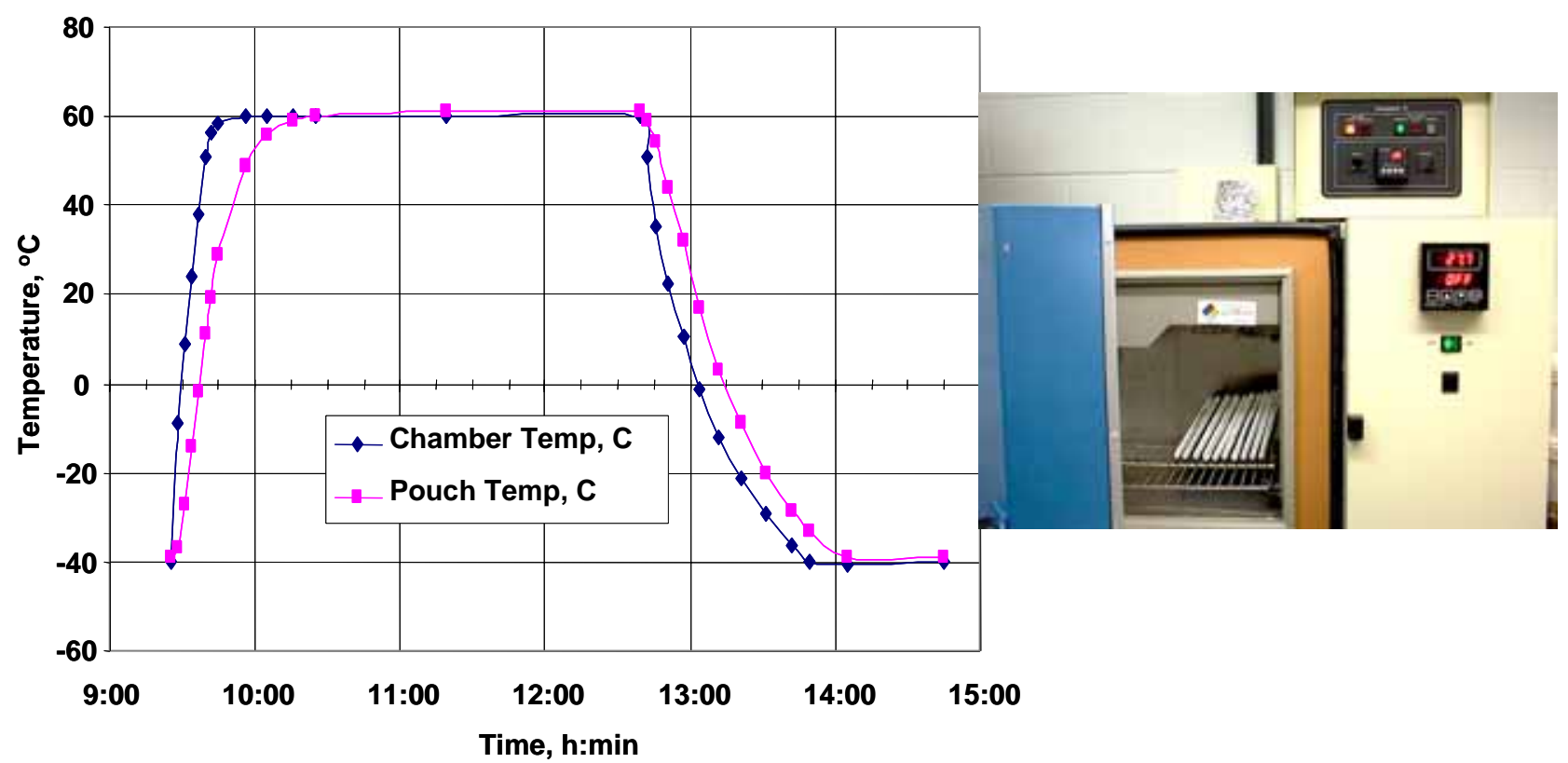

Figure 18. Temperature measurements inside pouch electrolyte and in Tenney Jr. temperature chamber for rapid thermal cycling in ambient humidity. 


\section{$\underline{\text { Results of Thermal Abuse Tests }}$}

The results to date for the $10 \mathrm{HEV}$-sized pouches undergoing rapid thermal cycling between $-40^{\circ} \mathrm{C}$ and $60^{\circ} \mathrm{C}$ are shown in Figure 19. Several of these pouches have reached more than 2400 thermal cycles without any signs of rupturing, delamination, or seam splitting. From the slope of these curves, the electrolyte loss rate was estimated to be 1.4 micrograms per thermal cycle per centimeter of perimeter. The perimeter length is used as the basis because it is assumed that no solvent, water, or air permeation occurs through the aluminum foil. As a worstcase scenario, if this $\mathrm{HEV}$-sized pouch $(59-\mathrm{cm}$ perimeter) was thermally cycled once a day between $-40^{\circ} \mathrm{C}$ and $60^{\circ} \mathrm{C}$, it would lose only 0.5 grams of electrolyte over the 15 -year life. This analysis ignores the influence of moisture uptake on the true electrolyte weight loss. The temperature will rarely cycle this extreme in actual use, but this analysis does provide an upper limit on the amount of electrolyte that is expected to be lost due to thermal cycling of the battery packaging. It also provides a useful check on the effects of the mismatch in coefficient of thermal expansions between the metals and polymers incorporated in these pouches, and on the effects of absorbed moisture and solvents crystallizing in the sealant/adhesive layer.

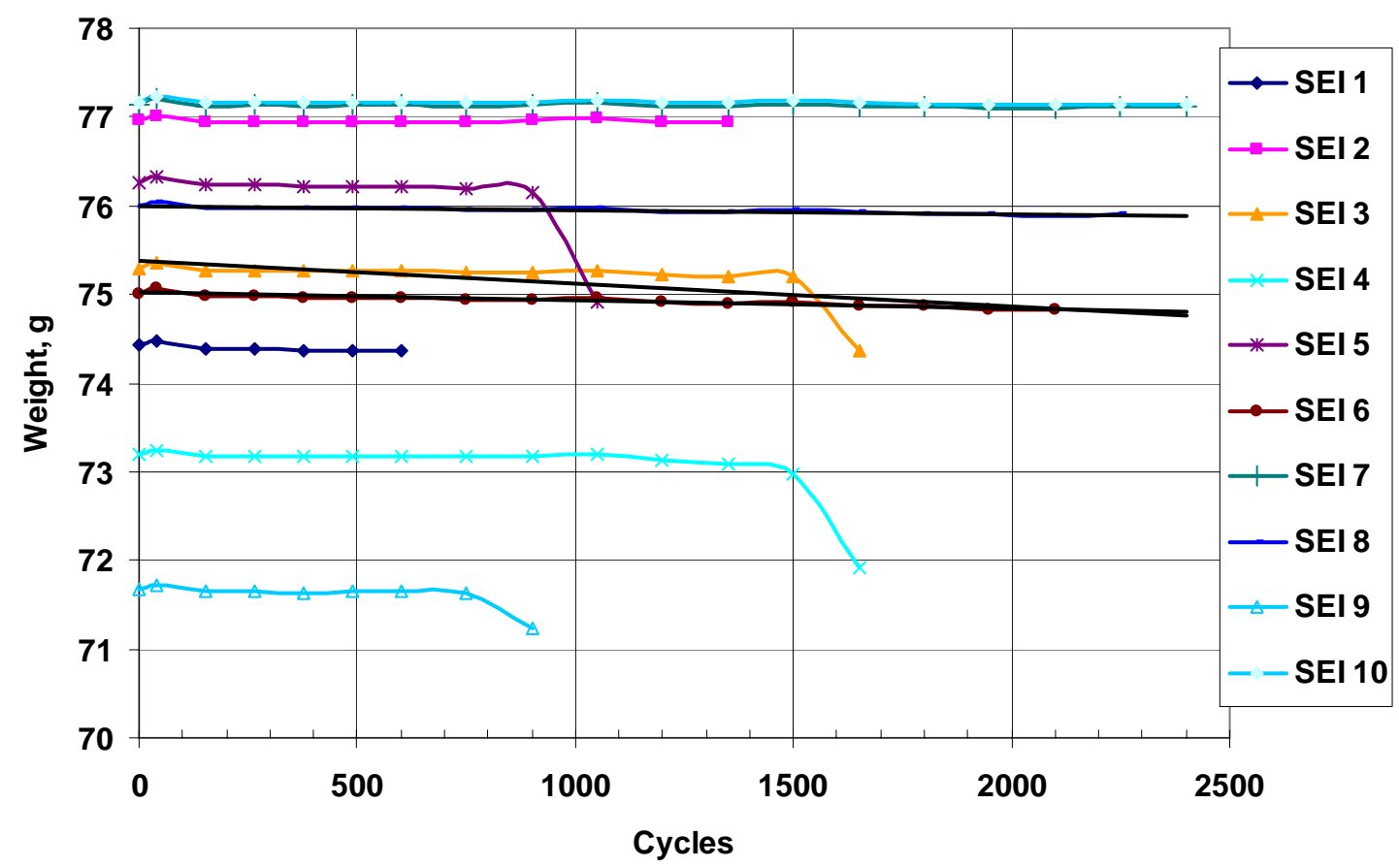

Figure 19. Weight of SEI's HEV-sized pouches undergoing rapid thermal cycling between $-40^{\circ} \mathrm{C}$ and $60^{\circ} \mathrm{C}$ in ambient humidity.

Several of the 13 pouches stored at $55^{\circ} \mathrm{C}$ and $83 \% \mathrm{RH}$ reached over 370 days without any signs of rupturing, delamination, or seam splitting. A slight weight loss is observed for these pouches as can be seen in Figure 20. From the slope of these curves, the electrolyte loss rate was estimated to be 8 milligrams per year per centimeter of perimeter. This implies that 7 grams of electrolyte would be loss for this HEV-sized pouch (59-cm perimeter) over the 15-year life if it was stored continuously at $55^{\circ} \mathrm{C}$. Of course, in actual use the average temperature will rarely be this high and, this assumes that each solvent component permeates at the same rate, which is 
unlikely. What this number does provide is an upper limit on the amount of electrolyte that is expected to be loss due to the containment vessel itself. However, the true electrolyte loss rate is not known because of the moisture uptake. This test ended after 370 days due to one pouch leaking electrolyte into the sealed humidity container, which contaminated the remaining pouches. It may be wise for developers to segregate these pouches so that one pouch rupturing does not ruin the others.

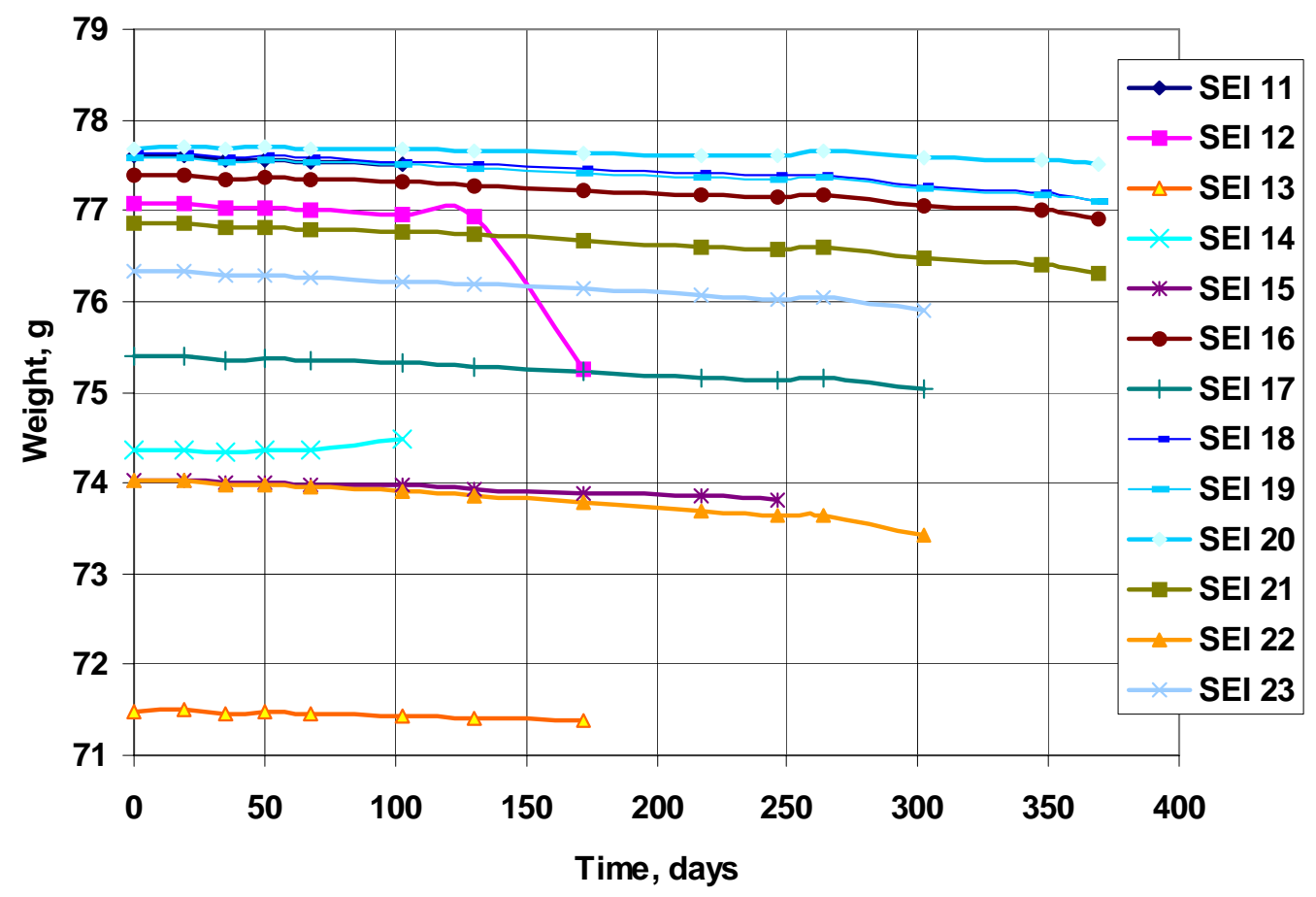

Figure 20. Weight of SEI's HEV-sized pouches undergoing storage at $55^{\circ} \mathrm{C}$ and $83 \% \mathrm{RH}$.

The 7 pouches undergoing summer/winter thermal cycling achieved 620 summer cycles and 200 winter cycles (Figure 21). The thought behind this thermal cycling profile was that the pouch material would retain moisture during the warm humid summer months and then crystallize as ice in the laminate layers during the winter months. As can be seen from Figure 20, there appears to be a slight weight gain during the summer profile and a slight weight loss during the winter profile. Over the course of the simulated year, the weight does not appear to vary far from its initial value. Unfortunately, one pouch leaked electrolyte into the sealed humidity container, which contaminated the remaining pouches and forced this test to end prematurely. 


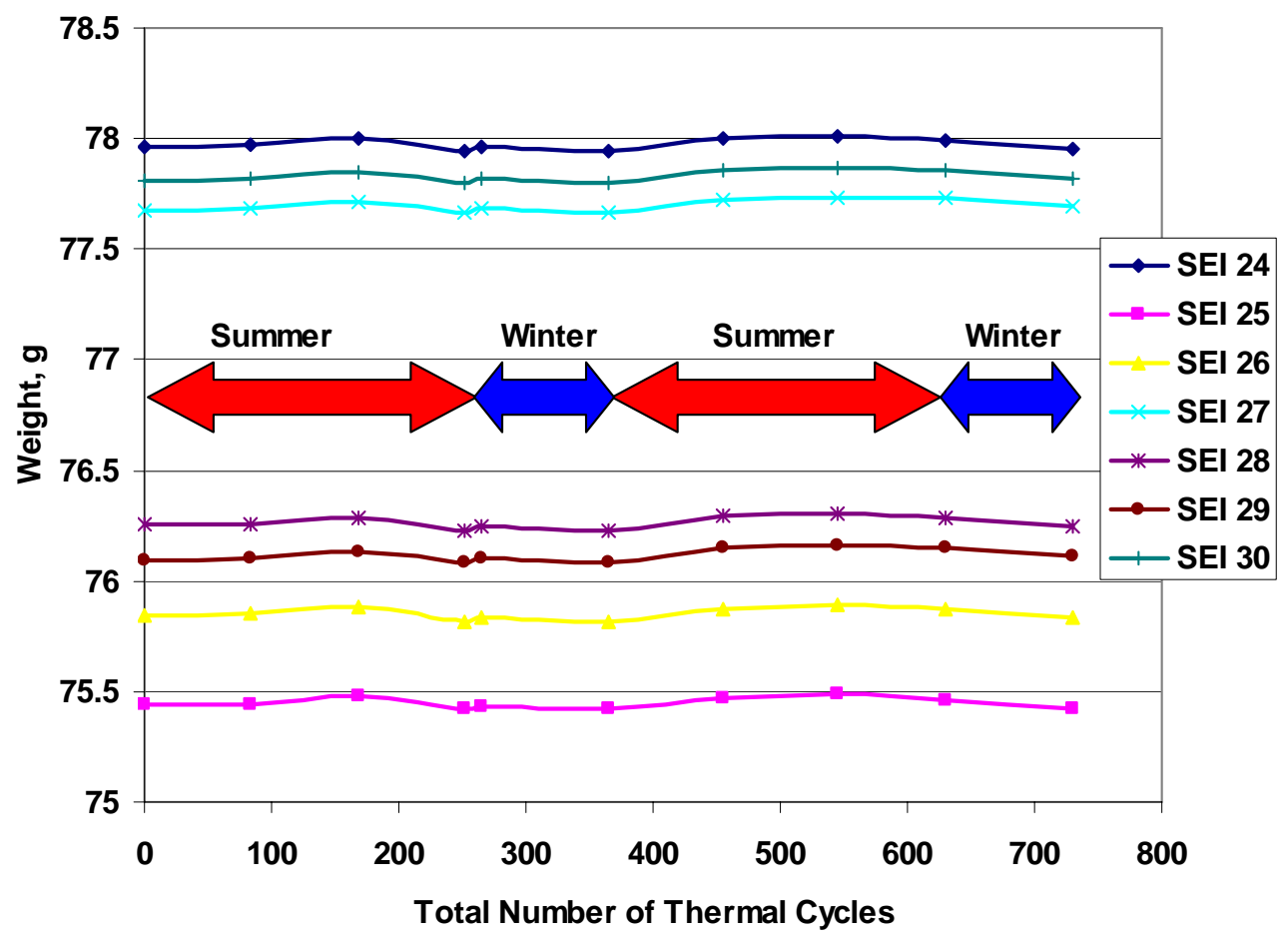

Figure 21. Weight of SEI's HEV-sized pouches undergoing summer/winter thermal cycling profile.

Several of the 30 pouches were removed because they showed signs of corrosion at the bottom corner where the pocket was formed. This defect was not due to failure of the packaging material itself, but rather because of the sharp radius of curvature at the pocket corners combined with a dimpling (creasing) at the pocket corner. The shallow creases were due to a lack of electrodes in the pouch. In a normal full cell, the electrodes would provide support to the pouch walls and prevent the pouches from "collapsing" during handling and shipping. Even for these pouches, no signs of delamination or seam splitting were observed. ANL staff visited SEI in March 2004 to discuss the next generation of pouches. SEI personnel indicated that they are in the process of increasing the thickness of the aluminum foil and increasing the radius of curvature at the pocket corners, which requires re-tooling. ANL will test the thermal abuse tolerance of this new generation of pouches when they become available. SEI was also asked to fabricate pouches with LiBOB electrolyte. Because HF acid does not form with this electrolyte, it will be a very useful test to determine the true moisture ingress into the pouch. An HF getter will not be incorporated into the sealant layer, which has the added benefit of reducing the laminate cost.

\section{$\underline{\text { Analysis of Electrolyte Samples }}$}

Several pouches were removed from each test scheme as scheduled for destructive analysis. Electrolyte was extracted from all of the removed pouches and the pouches were cut open for visual inspection. No sign of attack of the sealant layer or the seal around the electrode 
feed-throughs was evident. Samples of the electrolyte and of the inner (sealant) film were analyzed with FTIR. No changes in the IR spectra were observed for the film or for the electrolyte samples. The electrolyte samples were also analyzed for moisture, acidity, and color. These values are summarized in Tables 9 and 10. From these data it is apparent that storage at $55^{\circ} \mathrm{C}$ and $83 \% \mathrm{RH}$ is the most aggressive test protocol.

Further analysis of the data indicated that the moisture adsorbent that is incorporated into the sealant layer limits the level of moisture and acid in the electrolyte. However, the darkening of the electrolyte correlated well with the degree of thermal abuse despite nearly constant levels of moisture and acid for each test scheme. This suggests that the moisture adsorbent does not completely prevent decomposition of the electrolyte, but may limit its extent. Once the adsorbent is consumed (as in corroded pouches), moisture and, especially, acid levels and darkness rise significantly. It would appear that the moisture adsorbents only hold or restrain the water molecules; they do not neutralize or destroy them. The electrolyte may still diffuse to the held water molecule and react, instead of the water molecule diffusing to the electrolyte and reacting. The decomposition reaction still takes place but at a reduced rate because the water molecule is immobilized.

Table 9. Analysis of electrolyte from SEI's HEV-sized pouches that underwent rapid thermal cycling between $-40^{\circ} \mathrm{C}$ and $60^{\circ} \mathrm{C}$ in ambient humidity.

\begin{tabular}{|c|c|c|c|}
\hline Pouch & Moisture (ppm) & Acid \% (HF) & Color \\
\hline $\begin{array}{c}\text { SEl-0 } \\
\text { Un-cycled pouch }\end{array}$ & 28 & $\begin{array}{c}\mathbf{0 . 0 4 9} \\
(\mathbf{4 9 0} \mathbf{~ p p m )}\end{array}$ & \\
\hline $\begin{array}{c}\text { SEl-1 } \\
\text { C00 Rapid Thermal } \\
\text { Cycles (109 days) }\end{array}$ & 49 & $\mathbf{0 . 0 7 0}$ & \\
\hline $\begin{array}{c}\text { 1350 Rapid Thermal } \\
\text { Cycles (250 days) }\end{array}$ & 35 & $\mathbf{0 . 0 3 0}$ & \\
\hline $\begin{array}{c}\text { 2100 Rapid Thermal } \\
\text { Cycles (400 days) }\end{array}$ & 42 & 0.054 & \\
\hline
\end{tabular}


Table 10. Analysis of electrolyte from SEI's HEV-sized pouches that underwent storage at $55^{\circ} \mathrm{C}$ and $83 \% \mathrm{RH}$.

\begin{tabular}{|c|c|c|c|}
\hline Pouch & Moisture (ppm) & Acid \% (HF) & Color \\
\hline $\begin{array}{c}\text { SEI-0 } \\
\text { Un-cycled pouch }\end{array}$ & 28 & $\mathbf{0 . 0 4 9}$ \\
$\mathbf{( 4 9 0} \mathbf{~ p p m )}$ & \\
\hline $\begin{array}{c}\text { SEl-11 } \\
\text { Stored at } 55^{\circ} \mathrm{C} \text { and } \\
83 \% \mathrm{RH} \text { for } 103 \text { days }\end{array}$
\end{tabular}

\section{Influence of Moisture Adsorbents}

A few words should be considered here about the use of moisture adsorbents and their influence on test results. The SEI laminate incorporates a moisture adsorbent (and acid getter) in the sealant layer. Two processes are thus occurring that may confuse the weight loss results: weight gain from absorption of moisture from the air, and weight loss from permeation of electrolyte out of the pouch. This net balance will vary with temperature, humidity, and time. To demonstrate this point, several small $(76 \mathrm{~mm}$ x $76 \mathrm{~mm})$ pouches were made from SEI laminate stock at ANL and filled with electrolyte (2 $\mathrm{mL}$ of $1 \mathrm{M} \mathrm{LiPF}_{6}$ in EC/DEC/DMC/EMC/PC). Weight loss analysis was performed at three temperatures, $25^{\circ} \mathrm{C}, 37^{\circ} \mathrm{C}$, and $55^{\circ} \mathrm{C}$, with the pouches exposed to ambient air. The weight decreased with time in a very linear manner for the pouches at $37^{\circ} \mathrm{C}$ and $55^{\circ} \mathrm{C}$, but not for the pouch at $25^{\circ} \mathrm{C}$. Duplicate pouches were also made that confirmed this result. A permeation rate was obtained from the slope of each line. These results are summarized in Figures 22a and 22b. As can be seen from these graphs, there is a crossover point where the rate of electrolyte loss overcomes the rate of moisture uptake. It is for this reason that Test Protocol 2.1 was designed to accurately assess the true electrolyte loss rate. 

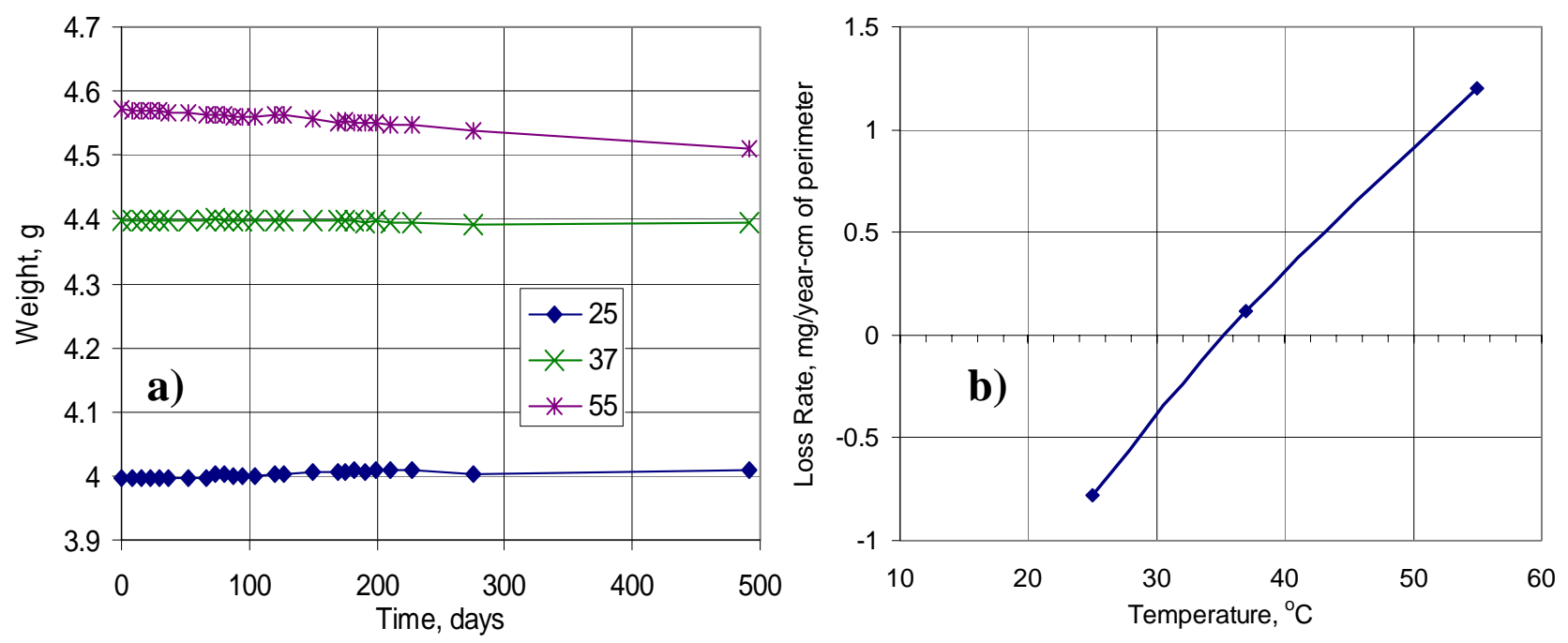

Figure 22. Electrolyte-filled small pouches made from SEI laminate stock: (a) weight vs. time at three temperatures and (b) loss rate vs. temperature. Note weight gain at $25^{\circ} \mathrm{C}$. 


\section{APPENDIX E: COMPANY CONTACT INFORMATION}

Following is an alphabetical list of companies with associated contact information:

Company Information

Chemetall Oakite

Oakite Products, Inc.

50 Valley Road

Berkeley Heights, NJ 07922

Tel: $\quad$ 800-526-4473

Fax: $\quad 908-464-4658$

E-mail: bob.ciesko@chemetall.com

Internet: www.oakite.com

Cotronics Corporation

3379 Shore Parkway

Brooklyn, NY 11235

Tel: $\quad$ 718-646-7996

Fax: $\quad 718-646-3028$

Internet: www.cotronics.com

Dovey Corporation

3220 W. $25^{\text {th }}$ Street

Anderson, IN 46011

Tel: $\quad 800-457-2576$

Fax: 800-424-2559

E-mail: csmythe@doveyco.com

Internet: www.doveyco.com

The Dow Chemical Company

2030 Dow Center

Midland, MI 48674

Tel: $\quad$ 1-800-441-4369

Fax: $\quad 989-636-3518$

Internet: www.dow.com

DuPont Polymers

Donna L. Visioli

Bob Ciesko
630-989-9541
Bob Ciesko
630-989-9541

$\underline{\text { Contact }}$

Chestnut Run Plaza

P.O. Box 80712

Wilmington, DE 19880-0712 
Tel: 302-999-2807

Eastman Chemical Company

100 North Eastman Road

Kingsport, TN 37662-5075

Tel: $\quad 423-229-2000$

Internet: www.eastman.com

EVAL Company of America

Hiroyuki Okubo

Two Corporate Plaza

2625 Bay Area Blvd., Ste. 300

Houston, TX 77058

Tel: $\quad$ 281-204-4635

Internet: ww.evalca.com

Henkel Surface Technologies

Chuck Rowan

32100 Stephenson Highway

708-267-2414

Madison Heights, MI 48071

Tel: $\quad$ 800-848-0085

Fax: 248-589-4629

Internet: www.buyhstna.com

Judd Wire Inc.

870 Los Vallecitos Blvd.

Koji Hanafusa

San Marcos, CA 92069-1479

Tel: $\quad$ 760-744-7720 Ext. 102

Fax: 760-744-6089

E-mail: khanafusa@juddwire.com

Internet: www.juddwire.com

Kapak Corp.

Sheldon Saffe

5305 Parkdale Drive

Minneapolis, MN 55416-1681

Tel: $\quad 952-693-2423$

Fax: 952-541-0735

E-mail: sheldons@kapak.com

Internet: www.kapak.com

(Loctite)

Henkel Loctite Corporation

1001 Trout Brook Crossing 
Rocky Hill, CT 06067

Tel: $\quad$ 800-562-8483

Fax: $\quad 860-571-5465$

Internet: www.loctite.com

Mitsui Chemicals America, Inc.

2500 Westchester Avenue, Suite 110

Purchase, NY 10577

Tel: $\quad$ 914-251-4239

Fax: $\quad$ 914-253-0790

Internet: www.mitsuichemicals.com

Mocon, Inc.

Dave Maki

7500 Boone Avenue North

Minneapolis, MN 55428

Tel: $\quad 763-493-7207$

Fax: $\quad 763-493-6358$

Internet: www.mocon.com

Pantheon Chemical

Wade Rohland

225 W. Deer Valley Road, No. 4

623-780-2296

Phoenix, AZ 85027-2108

Tel: $\quad$ 888-824-2918

Fax: 623-516-0414

E-mail: wrohland@pantheonchemical.com

Internet: www.pantheonchemical.com

Plastic Technology Partners

Stephen W. Cornell

605 Leesburg Ct.

Naperville, IL 60540

Tel: $\quad$ 630-357-2894

E-mail: scornell.ptp@juno.com

Rohm and Haas Company

Midwest Technical Center

2531 Technology Drive, Suite 301

Elgin, IL 60123

Tel: $\quad 847-649-3800$

Fax: $\quad 847-649-3760$

Internet: www.rohmhaas.com/AdhesivesSealants 
Rollprint Packaging Products, Inc.

Dhuanne Dodrill

320 Stewart Avenue

Addison, IL 60101-3310

Tel: $\quad 630-628-1700$

Fax: $\quad 630-628-8957$

E-mail: dhuanne@rollprint.com

Internet: www.rollprint.com

Sumitomo Electric Flat Components, Inc.

Takehiro Hosokawa

(A subsidiary of Sumitomo Electric Industries, LTD.)

3-3, Satsuki-cho, Kanuma,

Tochigi, 322-8585 Japan

Tel: $\quad$ 0289-76-0334

Fax: 0289-76-3485

E-mail: hosokawa@sei.co.jp

Internet: www.sei.co.jp

Voridian

Division of Eastman Chemical Company

1 James C. White Drive

Kingsport, TN 37662-5075

Tel: $\quad 423-229-1000$

Internet: www.voridian.com 
Distribution for ANL-04/09

Internal (Printed Copy Only):
A. N. Jansen
D. R. Vissers
A. J. Kahaian
K. Amine
P. A. Nelson
G. L. Henriksen (50)
D. P. Abraham
S.-H. Kang
D. W. Dees
I. Belharouak
J. Liu
M. M. Thackeray
D. J. Chaiko
J. T. Vaughey
I. D. Bloom
C. S. Johnson
J. F. Miller

Internal (Electronic Copy Only):

M. R. Hale, TIS

D. Lewis

\section{External (Printed Copy Only):}

M. Alamgir, Compact Power, Monument, CO

M. Andrew, Johnson Controls Inc., Milwaukee, WI

C. Ashtiani, DaimlerChysler, Rochester Hills, MI

T. Atwater, U.S. Army RDECOM, Fort Monmouth, NJ

J. Barnes, USDOE, Washington, DC

V. Battaglia, Lawrence Berkeley National Laboratory, Berkeley, CA

R. Brodd, Broddarp of Nevada, Inc., Henderson, NV

S. Cornell, Plastic Technology Partners, Naperville, IL

J. Deppe, Davidsonville, MD

J. DiCarlo, Lithion, Inc., Pawcatuck, CT

D. Dodrill, Rollprint Packaging Products, Inc., Addison, IL

D. Doughty, Sandia National Laboratories, Albuquerque, NM

T. Duong, USDOE, Washington, DC

K. Gering, INEEL, Idaho Falls, ID

M. A. Habib, General Motors Corp., Warren, MI

H. Haskins, Corvallis, OR

E. Heim, San Rafael, CA

M. Hoenigmann, Pliant Corp., Chippewa Falls, WI

T. Hosokawa, Sumitomo Electric Flat Components, Inc., Tochigi, Japan

D. Howell, USDOE, Washington, DC

T. R. Jow, Army Research Laboratory, Adelphi, MD

K. Kepler, Farasis Energy, Inc., Alameda, CA

V. Manev, Delphi Automotive Systems, Indianapolis, IN

F. R. McLarnon, Lawrence Berkeley National Laboratory, Berkeley, CA

T. Miller, Ford Motor Co., Dearborn, MI

R. Minck, Laguna Niguel, CA

T. Murphy, INEEL, Idaho Falls, ID

K. Nechev, SAFT America, Inc., Cockeysville, MD 
N. Pinsky, Southern California Edison, Rosemead, CA

N. Raman, SAFT America, Inc., Cockeysville, MD

H. Saen, Sumitomo Electric Flat Components, Inc., Tochigi, Japan

S. Saffe, Kapak Corp., Minneapolis, MN

V. Saharan, Delphi Corp., Flint, MI

W. Schank, Ford Motor Co., Dearborn, MI

L. Simmering, Ford Motor Co., Dearborn, MI

J. Stockel, NRO/CIA, Chantilly, VA

J. Symanski, Johnson Controls Inc., Milwaukee, WI

H. Tataria, General Motors Corp., Troy, MI

T. Tran, Sentech, Inc., Bethesda, MD

M. Verbrugge, General Motors Corp., Troy, MI

A. Webber, Energizer, Westlake, $\mathrm{OH}$

W.-S. Yoon, Brookhaven National Laboratory, Upton, NY

External (Electronic Copy Only):

M. A. Buckley, ANL Library-E

E. Sackett, ANL Library-W

Chemical Engineering Division Review Committee Members:

H. U. Anderson, University of Missouri-Rolla, Rolla, MO

C. L. Hussey, University of Mississippi, University, MS

M. V. Koch, University of Washington, Seattle, WA

V. P. Roan, Jr., University of Florida, Gainesville, FL

J. R. Selman, Illinois Institute of Technology, Chicago, IL

J. S. Tulenko, University of Florida, Gainesville, FL 